\title{
Poly(ADP-ribose) polymerase inhibition: past, present and future
}

\begin{abstract}
Nicola J. Curtin ${ }^{1 凶}$ and Csaba Szabo ${ }^{2 \otimes}$
Abstract | The process of poly(ADP-ribosyl)ation and the major enzyme that catalyses this reaction, poly(ADP-ribose) polymerase 1 (PARP1), were discovered more than 50 years ago. Since then, advances in our understanding of the roles of PARP1 in cellular processes such as DNA repair, gene transcription and cell death have allowed the investigation of therapeutic PARP inhibition for a variety of diseases - particularly cancers in which defects in DNA repair pathways make tumour cells highly sensitive to the inhibition of PARP activity. Efforts to identify and evaluate potent PARP inhibitors have so far led to the regulatory approval of four PARP inhibitors for the treatment of several types of cancer, and PARP inhibitors have also shown therapeutic potential in treating non-oncological diseases. This Review provides a timeline of PARP biology and medicinal chemistry, summarizes the pathophysiological processes in which PARP plays a role and highlights key opportunities and challenges in the field, such as counteracting PARP inhibitor resistance during cancer therapy and repurposing PARP inhibitors for the treatment of non-oncological diseases.
\end{abstract}

The nuclear enzyme poly(ADP-ribose) polymerase 1 (PARP1) was first described more than 50 years ago ${ }^{1-3}$ and is now known to play important roles in DNA repair and the maintenance of genome integrity, as well as in the regulation of multiple metabolic and signal transduction processes in health and disease ${ }^{1-5}$. It catalyses the transfer of ADP-ribose residues from $\mathrm{NAD}^{+}$onto target substrates, building a poly(ADP-ribose) (PAR) chain (FIG. 1a). The building up of PAR chains and the removal of these chains - principally by poly(ADP-ribose) glycohydrolase (PARG) and ADP-ribosylhydrolase 3 (ARH3) - occurs in almost all eukaryotic cells. PARP1 was the first member of a superfamily of ADP-ribosylating enzymes, which consists of proteins that have homology to PARP1 and that, in general, are capable of catalytic ADP-ribosyltransferase reactions (the structure of PARP1 is shown in FIG. 1 b). The family now has 17 members, four of which - PARP1, PARP2, PARP5A and PARP5B - are capable of synthesizing PAR chains ${ }^{1-3}$. Most of the other enzymes in the family build only single ADP-ribose units and are therefore classified as mono(ADP-ribosyl)ases (MARs).

Since the 1970s, the field of PARP biology has expanded dramatically, with more than 20,000 articles published to date. Some of the major milestones in preclinical PARP research relating to the discovery of pharmacological PARP inhibitors and the delineation of their molecular modes of action ${ }^{6-63}$ are shown in FIG. 2. Early milestones in PARP research include the discovery of PAR, the elucidation of its structure and the discovery that PARP1 produces $\mathrm{PAR}^{6-8}$. Subsequent studies described the purification of PARP1 (REF. ${ }^{10}$ ), showed PARP activation in response to genotoxic agents ${ }^{11,12}$, linked PARP1 to DNA repair ${ }^{15}$ and demonstrated the association of PAR with chromatin, histones and nuclear enzymes including PARP1 itself ${ }^{8,9}$. The generation and characterization of the Parp1-knockout mouse ${ }^{24,29,64}$ was instrumental in the discovery of PARP2, and subsequently additional members of the PARP superfamily were identified ${ }^{46}$.

Specialized aspects of PARP biology have been summarized in other reviews, including PARP biochemistry ${ }^{65,66}$, PARP molecular biology $y^{67,68}$ and the role of PARP in DNA repair $^{69,70}$, carcinogenesis $^{71,72}$, metabolism ${ }^{73,74}$, signalling ${ }^{75,76}$, cell death ${ }^{77,78}$, gene transcription ${ }^{78,79}$ and ageing ${ }^{80,81}$. This Review focuses specifically on the parallel evolution of two therapeutic concepts: the inhibition of PARP in order to interfere with DNA repair and induce tumour cell death for the treatment of oncological diseases and the inhibition of PARP to maintain cellular bioenergetics and suppress proinflammatory signalling for the treatment of non-oncological diseases. The evolution of these two concepts has occurred in parallel with advances with PARP inhibitor medicinal chemistry to produce more potent PARP inhibitors, some of which have entered clinical trials and been approved for treating various cancers (REFS ${ }^{82-98}$; TABLE 1, reviewed in REFS ${ }^{99-101}$ ). In this Review, after briefly summarizing the key advances in PARP biology, we outline the progress made towards therapeutically targeting PARP in 
a

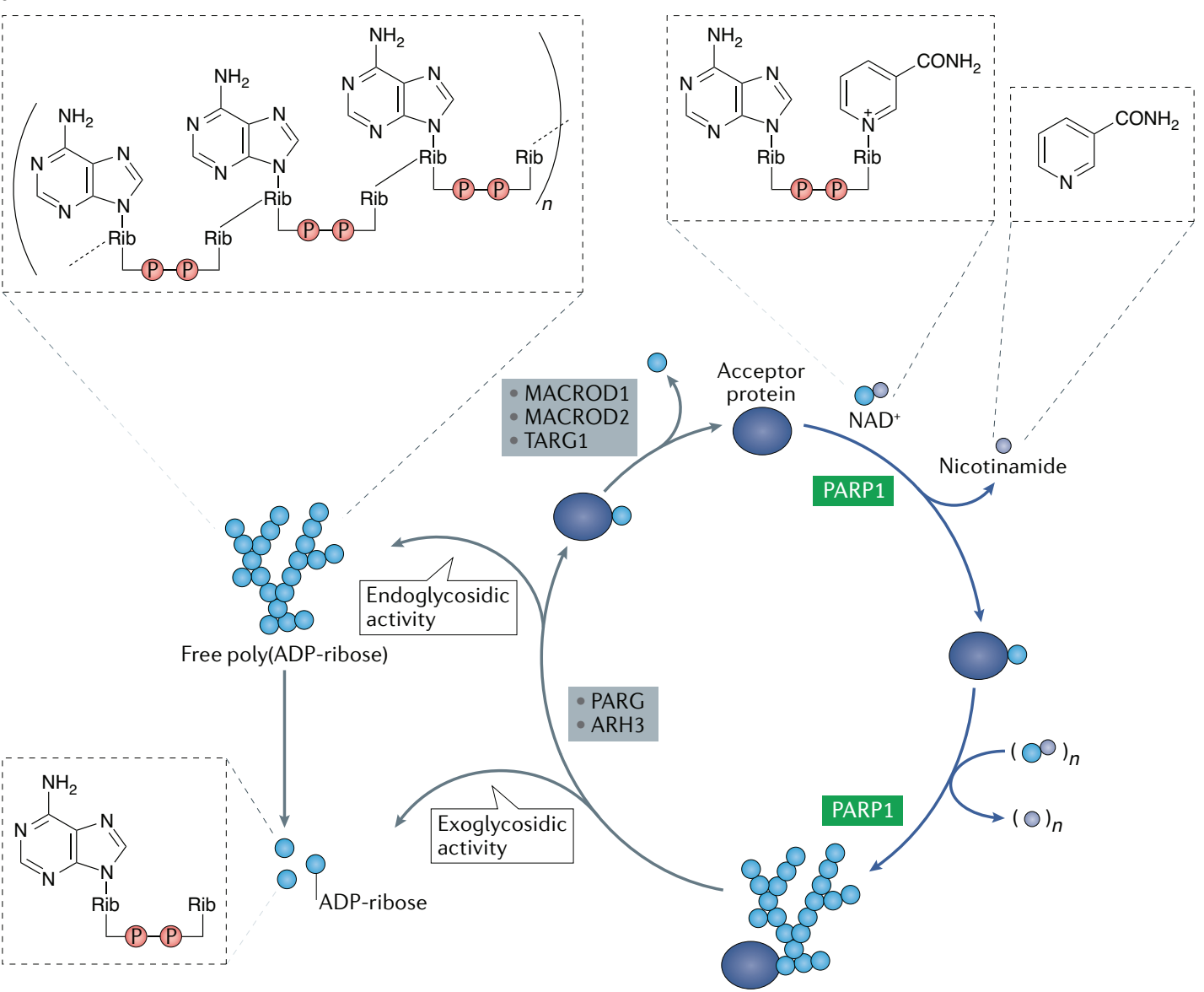

b

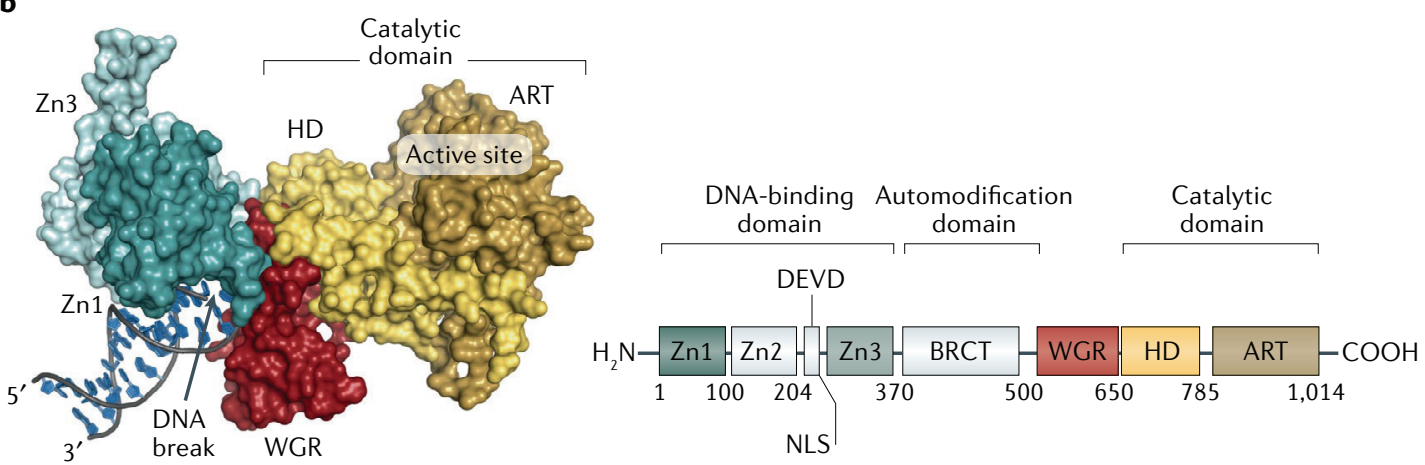

Fig. 1 | PARylation, PAR removal and the structure of PARP1. a | Enzymatic poly(ADP-ribose) (PAR) build-up and PAR degradation processes. Poly(ADP-ribose) polymerase 1 (PARP1) cleaves NAD+ to ADP-ribose and nicotinamide, and covalently attaches ADP-ribose to an acceptor protein. Additional $\mathrm{NAD}^{+}$molecules can be cleaved and build up linear and branched forms of PAR. Two enzymes, poly(ADP-ribose) glycohydrolase (PARG) and ADP-ribosylhydrolase 3 (ARH3), play central roles in the degradation of PAR through their exoglycosidic and endoglycosidic activities. The ADP-ribose glycohydrolases MACROD1, MACROD2 and TARG1 act on mono(ADP-ribosyl)ated peptides generated by PARG. Free PAR can also be degraded to mono(ADP-ribose). $\mathbf{b} \mid$ A surface representation of PARP1 binding to damaged DNA is shown on the left and the modular organization of human PARP1 is shown on the right. The amino-terminal DNA-binding domain contains three zinc-finger domains, which mediate DNA binding and some protein-protein interactions, and a nuclearlocalization signal (NLS) in the caspase cleavage site (DEVD). The central automodification domain contains a breast cancer-susceptibility protein-carboxy terminus (BRCT) motif, which mediates protein-protein interactions. The role of the tryptophan-glycine-arginine-rich (WGR) domain is not fully understood, although it likely represents a nucleic acid-binding domain. The carboxy-terminal catalytic domain contains two subdomains: a helical domain (HD), and the ADP-ribosyltransferase (ART) domain, which is located between residues 785 and 1,014, contains the active NAD+-binding site and is conserved in all PARP family members. PARylation, poly(ADP-ribosyl)ation. Part $\mathbf{b}$ adapted with permission from REF. ${ }^{54}$, AAAS. 
cancer and in non-oncological diseases, with a focus on current challenges and emerging opportunities. We finally highlight the potential of targeting other PARP family members, such as PARP5A and PARP5B (also known as tankyrase 1 and tankyrase 2, respectively), PARP3 and PARP7. This Review focuses primarily on the inhibition of PARP1, as this enzyme is responsible for most mammalian PARylation, and inhibition of this enzyme has emerged as a translational and clinical strategy. Throughout this Review, 'PARP' generally refers to PARP1; when we are discussing pharmacological 'PARP inhibitors' these agents can inhibit other PARP isoforms, although the potential contributions of the inhibition of different PARP isoforms to the therapeutic effects of PARP inhibitors are unknown.

\section{Key advances in PARP biology}

PARP inhibition suppresses DNA repair. The role of PARP1 in relation to DNA repair was first postulated in 1975 (REF. ${ }^{102}$ ), and DNA-methylating agents and ionizing radiation were indentified as potent activators of PARP1 soon after ${ }^{11,103,104}$. However, it was not until the discovery of the first PARP inhibitors, in the late $1970 \mathrm{~s}^{13}$, that its function could be explored. These early inhibitors - 3-substituted benzamides, including 3-aminobenzamide (3-AB) - were based on nicotinamide, a weak inhibitor of PARP1 and a by-product of the PARP reaction converting $\mathrm{NAD}^{+}$to PAR (FIG. 1). Virtually all PARP inhibitors described to date contain the nicotinamide pharmacophore (see TABLE 1 for examples). 3-AB allowed further exploration of PARP1's function; a seminal article showed that 3-AB inhibited $\mathrm{NAD}^{+}$depletion, slowed DNA repair and decreased the survival of cells treated with the DNA-methylating agent dimethyl sulfate ${ }^{15}$. Subsequently, $3-\mathrm{AB}$ was shown to inhibit the repair of radiation-induced DNA damage and prevent recovery from the effects of potentially lethal ionizing radiation ${ }^{105}$, consistent with earlier data showing that DNA-alkylating agents and radiation are potent PARP activators. More potent PARP inhibitors developed in the 1990s were used to show that PARP inhibition slowed the repair of DNA damage caused by topoisomerase 1 poisons - which prevent the re-ligation of DNA single-strand breaks (SSBs) created by topoisomerase 1 - and increased the cytotoxicity of these agents, but not that of topoisomerase 2 poisons or antimetabolites ${ }^{85,86}$.

PARP1 is best known for its role in DNA SSB repair (SSBR). SSBs can be formed directly through cleavage of the ribose-phosphate backbone by radiation, free radicals or oxidants, or by enzymatic cleavage of DNA by topoisomerase 1 poisons. SSBs can also be formed indirectly following the excision of damaged bases for example, those that are methylated or oxidized - by glycosylases and cleavage of the resulting abasic site by an endonuclease $e^{106,107}$. PARP1 recognizes the SSB through its DNA-binding domain, which contains three zinc-finger motifs. The binding of PARP1 zinc-finger 2 to the DNA causes a conformational change that activates PARP1 to cleave $\mathrm{NAD}^{+}$into nicotinamide and an ADP-ribose moiety. The ADP-ribose moiety covalently attaches to either PARP1 or other nuclear proteins, such as histones; other ADP-ribose groups are then added to it to produce long and sometimes branching PAR chains. These negatively charged polymers initially recruit the DNA repair protein XRCC1 to the site of the break, presumably through electrostatic attraction, and cause the PARylated histones and PARP1 to dissociate from the break through electrostatic repulsion, allowing the rest of the SSBR machinery to access the DNA. Digestion of PAR by PARG and ARH3 allows histones to reassociate with DNA and allows PARP1 to attach to other breaks and start the SSBR process again in another location $^{108,109}$. XRCC1 recruits bifunctional polynucleotide kinase/phosphatase (PNKP) and aprataxin (APTX), which process the DNA ends so that DNA polymerase- $\beta$ can fill the gap and DNA ligase 3 can join the ends. If several nucleotides are replaced during processing and gap filling, then flap endonuclease 1 (FEN1) is also recruited and DNA ligase 1 may seal the ends (reviewed in REF. ${ }^{108}$ ).

PARP1 has been implicated in DNA repair pathways other than SSBR (as reviewed in REFS ${ }^{110-112}$ ), including the repair of DNA double-strand breaks (DSBs) by non-homologous end joining (NHEJ) and alternative end joining, which involves enzymes common to SSBR such as XRCC1, DNA ligase 3 and FEN1, as well as DSB repair protein MRE11 and the DNA repair and telomere maintenance protein NBS1. PARP1 has also been associated with classical NHEJ, which involves the dimeric protein complex Ku70-Ku80 and DNA-dependent protein kinase catalytic subunit (DNA-PKcs). However, the importance of PARP1 to these pathways is not completely clear. Although PARP1 is activated by ionizing radiation - which causes DNA DSBs and SSBs - PARP inhibitors are modest radiosensitizers. Furthermore, PARP inhibitors fail to sensitize cells to topoisomerase 2 poisons, which primarily cause DSBs - suggesting PARP is not involved in DSB repair ${ }^{113,114}$. There is some suggestion that PARP1 might promote nucleotide excision repair in response to UV radiation and cisplatin, although the evidence for PARP inhibitor-mediated increases in UV or cisplatin cytotoxicity is variable and cell line/experimental system dependent. For cisplatin at least, the enhancement of cytotoxicity by PARP inhibitors may reflect the homologous recombination repair (HRR) status of the cell ${ }^{115}$. A role for PARP in HRR itself has also been proposed, protecting stalled forks and promoting the restart of DNA synthesis; however, the data are conflicting because in the absence of PARP1, or in the presence of a PARP inhibitor, HRR is increased ${ }^{116-118}$. Further studies have suggested a role for PARP1 and its recruitment of XRCC1 in repairing unligated Okazaki fragments during DNA replication ${ }^{119}$.

PARP inhibitors inhibit DNA repair through PARP trapping. Inhibition of PARP activity has a greater impact on DNA repair than the lack of the enzyme itself. This was first demonstrated in a 1992 stud $^{21}$ that showed that nuclear extracts depleted of PARP1 can repair nicked plasmid DNA, but complete nuclear extracts deprived of $\mathrm{NAD}^{+}$or containing the PARP inhibitor 3-AB cannot. The study authors hypothesized that PARP1 was binding to the nicked DNA, but failed to dissociate in 


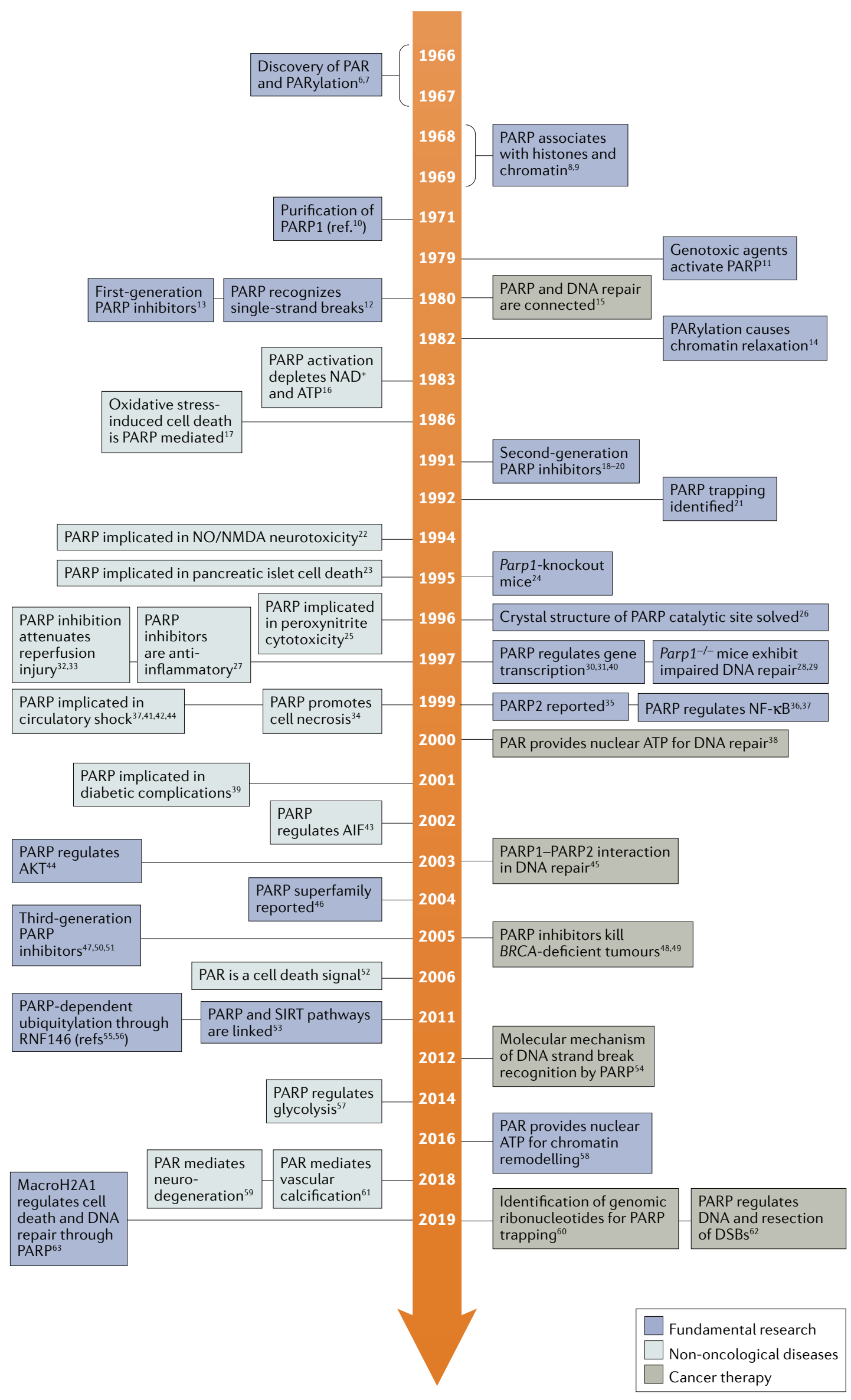


4 Fig. 2 | Selected preclinical PARP research milestones. Research on poly(ADP-ribose) polymerase (PARP) culminated in the formation of two distinct therapeutic concepts: the targeting of non-transformed cells to preserve cellular energetic pools, produce cytoprotective actions and suppress proinflammatory mediator production in various acute and chronic non-oncological diseases (non-oncological diseases), and the use of PARP inhibitors to suppress DNA repair and tumour growth (cancer therapy). Key basic discoveries, such as the emergence of different classes of PARP inhibitor, are also shown (fundamental research). The timeline of PARP biology was comprehensively reviewed by Kraus in 2015 (REF.2). AIF, apoptosis-inducing factor 1; DSB, double-strand break; NF-kB, nuclear factor-kB; NMDA, N-methyl-D-aspartate; NO, nitric oxide; PAR, poly(ADP-ribose); PARylation, poly(ADP-ribosyl)ation; SIRT, sirtuin.

the absence of catalytic activity, thereby blocking DNA repair. Additionally, Parp1-knockout mice were found to be viable and fertile $e^{24,29,64}$, implying that PARP1 is not necessary for viability and that PARP inhibitors might not be toxic. Further studies confirmed the 1992 data, and the term 'PARP trapping' was coined to refer to the prevention of PARP1 dissociation from the DNA in the presence of a PARP inhibitor ${ }^{120,121}$. PARP inhibitors differ in their ability to induce PARP trapping; for example, although the clinically approved PARP inhibitors olaparib, rucaparib and talazoparib have similar catalytic inhibitory potencies, talazoparib is around 100 -fold more potent at PARP1 trapping than the other inhibitors ${ }^{122}$. Recent studies suggest that whereas talazoparib and olaparib interact allosterically with PARP1 in a way that modestly inhibits the dissociation of PARP1 from DNA, rucaparib, niraparib and veliparib interact in a way that promotes dissociation by a factor of 3-5. However, for all inhibitors, inhibition of the catalytic activity of PARP1 and prevention of autoPARylation are important factors promoting dissociation ${ }^{123}$. It is likely that the cytotoxic effects of inhibitors are the product of these complex interactions. The capacities of these inhibitors to influence trapping and polymer formation are likely to mediate their cytotoxicity, especially in cases where the inhibitor is used as a single agent in homologous recombination-deficient cells or as a chemosensitizer for DNA-methylating agents. The capacity of inhibitors to influence PARylation is thought to be more important for the sensitization of cells to topoisomerase 1 poisons ${ }^{124}$. The nature of the DNA breaks - for example, whether they are endogenously induced SSBs, unligated Okazaki fragments, downstream SSBs following the removal of a methylated base or an SSB with one end attached to topoisomerase 1 may inform the relative importance of trapping and catalytic inhibition.

The two faces of PARP inhibition. Following studies demonstrating that PAR can recruit DNA repair enzymes to the site of DNA injury and coordinate their activity, a novel therapeutic concept emerged: by inhibiting PARP, it may be possible to suppress DNA repair and induce the death of cancer cells. In parallel with the growing appreciation of PARP1 as a therapeutic target in cancer, studies described an additional, energetic role for PAR in providing ATP to DNA repair enzymes to ensure successful DNA repair ${ }^{38,125}$, implicating PARP as an ancient 'stress response' mechanism capable of redirecting cellular energetic pools from the cytosol to the nuclear compartment. Studies in the early 1980s showed that PARP1 activation in response to DNA-damaging agents is associated with the depletion of cellular $\mathrm{NAD}^{+}$ and ATP, which can be prevented by pharmacological inhibition of PARP1 (REF. ${ }^{16}$ ). PARP-mediated bioenergetic defects were subsequently shown to develop in response to endogenous genotoxic agents such as hydroxyl radicals and peroxynitrite, which are produced in a variety of pathophysiological conditions $s^{17,25}$. Further studies showed that prolonged or extensive PARP1 activation can promote a regulated form of cell necrosis ${ }^{34}$. From these observations, an additional therapeutic concept emerged: by inhibiting PARP, it may be possible to maintain cell viability in oxidatively stressed or nitrosatively stressed cells and thereby induce cytoprotection and organ preservation in various nononcological diseases (note that PARP-mediated necrosis is not to be confused with the role of PARP1 as a substrate for cleavage during apoptosis ${ }^{126,127}$; see BOX 1). In the following sections, we separate the distinct pathophysiological mechanisms involved in oncological and non-oncological diseases and review the mechanisms and processes by which PARP inhibition exerts therapeutic effects in these conditions.

\section{PARP inhibition in oncology}

PARP inhibitors as chemosensitizers and radiosensitizers. In the 1990s and early 2000s, PARP inhibitors were predominantly developed with the aim of increasing the anticancer activity of ionizing radiation and chemotherapy drugs ${ }^{99,128}$. PARP inhibitors were first shown to sensitize cancer cells to DNA-methylating agents; chemosensitization was then observed with the topoisomerase 1 poisons camptothecin, topotecan and irinotecan in vitro and in vivo. In advanced preclinical studies, coadministration of the PARP inhibitor AG14361 or AG014699 (now known as rucaparib) with the alkylating agent temozolomide resulted in complete tumour regression for more than 60 days in mice ${ }^{50,129}$. These data led to the first clinical trial of a PARP inhibitor in patients with cancer in 2003 (REF. ${ }^{130}$ ), which established that rucaparib at a dose of $12 \mathrm{mg} \mathrm{m}^{-2}$ could safely be given with a full dose of temozolomide ${ }^{130}$, although myelosuppression - typically seen with temozolomide therapy - was observed in treated patients. Despite promising preclinical data, clinical studies have largely been associated with high toxicity (reviewed in REF. ${ }^{131}$ ). Studies have shown that PARP inhibitors can also sensitize cells to platinum-based agents, although this effect seems to be cell line dependent and as both PARP inhibitors and platinum-based agents alone cause profound cytotoxicity in HRR-defective cells, chemosensitization may be due to an additive toxic effect on defects in $\mathrm{HRR}^{115}$.

Numerous models have shown PARP inhibitors can sensitize cells to ionizing radiation ${ }^{131,132}$, reflecting the fact that ionizing radiation causes SSBs that are repaired by SSBR. The scientific foundation of PARP inhibitor combination therapy, as well as the current status of PARP inhibitor chemotherapy trials and radiotherapy trials, has been reviewed in more detail elsewhere $^{131-134}$. So far, no PARP inhibitor has been approved 
Table 1 | Notable PARP inhibitors, from first-generation inhibitors to approved drugs

\begin{tabular}{|c|c|c|}
\hline Compound name & $I_{50} \quad$ Structure & Notes \\
\hline \multicolumn{3}{|c|}{ First-generation PARP inhibitors } \\
\hline Nicotinamide & $210 \mu \mathrm{M} \quad \mathrm{O}_{3}$ & $\begin{array}{l}\text { A weak PARP inhibitor and the by-product of the PARP reaction }{ }^{10,11} \text {. } \\
\text { In cell-based studies, high }(\mathrm{mM}) \text { concentrations are required to inhibit } \\
\text { PARP. Has many pharmacological actions other than inhibiting PARP } \\
\text { Virtually all PARP inhibitors contain the nicotinamide pharmacophore }\end{array}$ \\
\hline 3-aminobenzamide & $33 \mu \mathrm{M}$ & $\begin{array}{l}\text { A weak PARP inhibitor }{ }^{13,20} \text {. In cell-based studies, high (mM) } \\
\text { concentrations are required to inhibit PARP. Many other members } \\
\text { of the benzamide class are PARP inhibitors. Benzamides have many } \\
\text { additional pharmacological actions, including free radical scavenging }\end{array}$ \\
\hline \multicolumn{3}{|c|}{ Second-generation PARP inhibitors } \\
\hline PD128763 & $420 \mathrm{nM} \quad \mathrm{O}$ & $\begin{array}{l}\text { Originally developed by Warner-Lambert } \mathrm{t}^{18} \text { and characterized as a } \\
\text { cytoprotective agent }{ }^{83} \text { and a chemosensitizer and radiosensitizer }{ }^{19} \text {. } \\
\text { In vivo adverse effects of the compound include hypothermia }{ }^{44}\end{array}$ \\
\hline
\end{tabular}

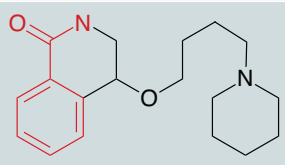

A commonly used Warner-Lambert PARP inhibitor compound based on an isoquinoline core ${ }^{18}$

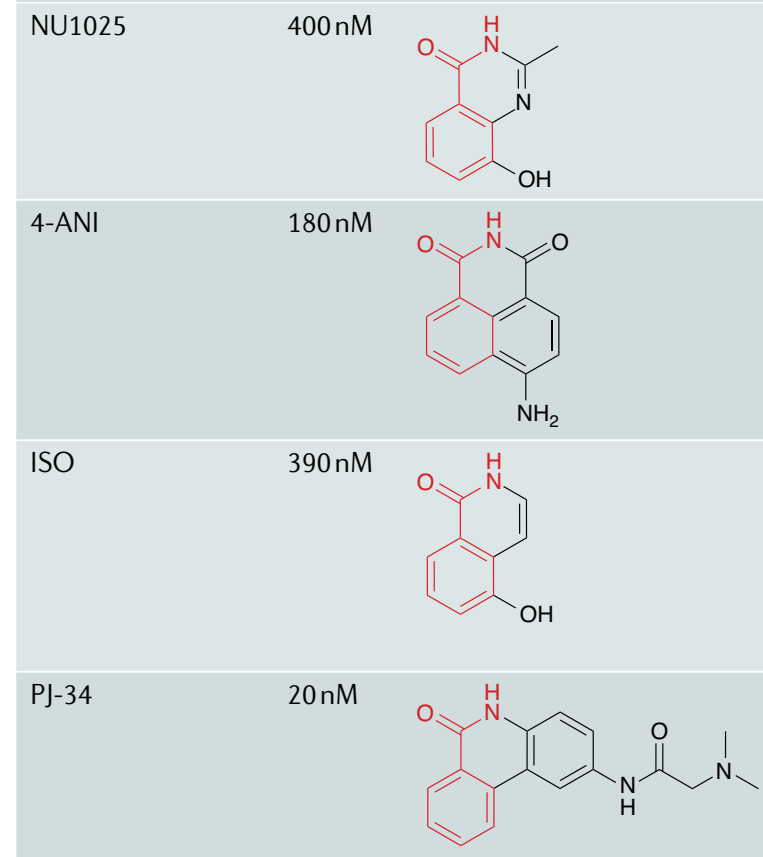

An example of a series of quinazoline compounds discovered by a group at Newcastle University that act as potentiators of anticancer agent cytotoxicity ${ }^{85,86}$

Third generation, FDA-approved PARP inhibitors

Olaparib
(Lynparza)


Table 1 (cont.) | Notable PARP inhibitors, from first-generation inhibitors to approved drugs

\begin{tabular}{|c|c|c|}
\hline Compound name & Structure & Notes \\
\hline \multicolumn{3}{|c|}{ Third generation, FDA-approved PARP inhibitors (cont.) } \\
\hline Niraparib (Zejula) & $4 \mathrm{nM}$ & $\begin{array}{l}\text { Discovered and characterized by Merck Inc. } .^{90} \text { and licensed to Tesaro } \\
\text { in 2012, who obtained regulatory approval. Achieved FDA approval ir } \\
\text { March } 2017 \text { for maintenance therapy in ovarian cancer. Tesaro was } \\
\text { acquired by GlaxoSmithKline in } 2019\end{array}$ \\
\hline $\begin{array}{l}\text { Talazoparib } \\
\text { (Talzenna) }\end{array}$ & $0.6 \mathrm{nM}$ & $\begin{array}{l}\text { Discovered by LEAD Therapeutics }{ }^{91} \text {. FDA approval granted in } \\
\text { October } 2018 \text { for use in germ line BRCA-mutant, HER2-negative } \\
\text { locally advanced or metastatic breast cancer }\end{array}$ \\
\hline Veliparib (ABT-888) & $2 \mathrm{nM}$ & $\begin{array}{l}\text { Discovered by Abbott }{ }^{92} \text {, who, in 2013, moved it to a spin-off company } \\
\text { AbbVie. AbbVie obtained regulatory approval and is responsible for } \\
\text { marketing and further development. Received orphan drug status } \\
\text { for lung cancer in November } 2016\end{array}$ \\
\hline
\end{tabular}

\title{
Additional, clinical-stage third-generation PARP inhibitors
}

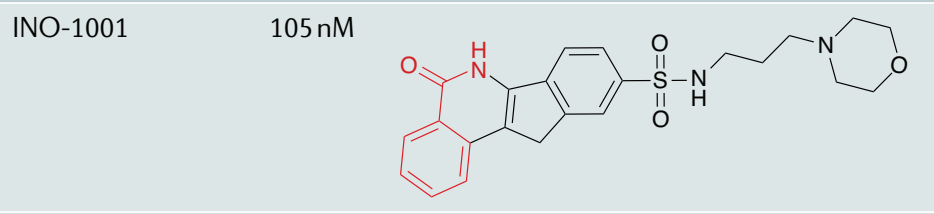

Discovered at Inotek Pharmaceuticals ${ }^{47}$, who advanced it to clinical trials in 2003. Licensed by Genentech in 2005, who have now terminated its development. Remains a preclinical experimental tool

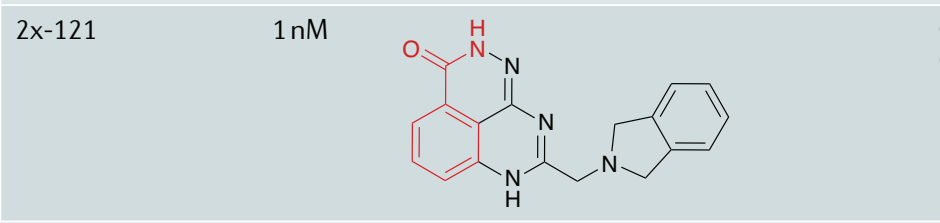

\begin{abstract}
Originally discovered by Eisai ${ }^{93}$. Currently being developed by Oncology Venture
\end{abstract}

CEP-8983

$20 \mathrm{nM}$

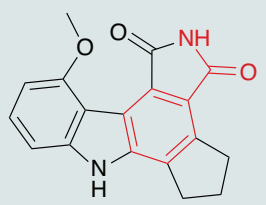

$0.83 \mathrm{nM}$

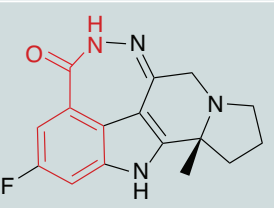

Fluzoparib

(SHR-3162)

$1.5 \mathrm{nM}$

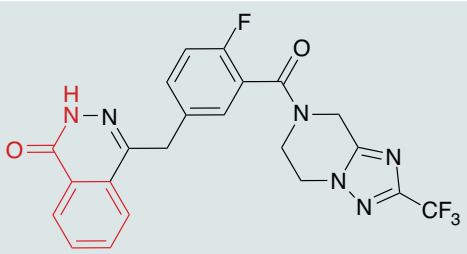

Amelparib (JPI-289) $18 \mathrm{nM}$

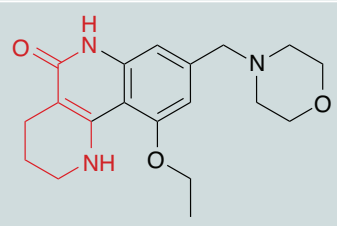

Originally discovered by Cephalon ${ }^{94}$ and currently being clinically evaluated by Checkpoint Therapeutics. A novel 4-methoxycarbazole PARP inhibitor with potential antineoplastic activity. Administered as its prodrug CEP-9722

Currently in clinical trials conducted by BeiGene as a single-agent and combination therapy for ovarian cancer and other solid tumours ${ }^{9}$

Currently in clinical trials conducted by Jiangsu HengRui Medicine in patients with germ line BRCA1/BRCA2 mutations and recurrent, platinum-sensitive ovarian cancer $^{96}$

Discovered by Jeil Pharmaceuticals ${ }^{97}$ and currently in clinical trials in patients with stroke

In addition, IMP4297 is in clinical trials conducted by Impact Therapeutics in patients with advanced ovarian, breast, prostate and other solid tumors ${ }^{98}$, and IDX-1197 (formerly NOV-1401) is in early-stage clinical trials conducted by ldience in patients with cancer (structures not available). The half-maximal inhibitory concentrations ( $\left(\mathrm{C}_{50}\right.$ values) presented are not always directly comparable owing to differences in assay conditions. Red coloration of the bond highlights the conserved nicotinamide pharmacophore. Some commercial vendors incorrectly list INO-1001 as 3-aminobenzamide. Iniparib (Sanofi), a late-stage clinical development molecule that was subsequently found not to have significant inhibitory effect on poly(ADP-ribose) polymerase (PARP), is not discussed in this Review. HER2, human epidermal growth factor receptor 2 . 
in combination with either conventional chemotherapy or radiotherapy.

The role of PARP in cancer cells with BRCA mutations and 'synthetic lethality'. In 1995, Lindahl et al. showed that PARP inhibitors cause an increase in homologous recombination events. They suggested that when PARP1 functions normally, the negatively charged ADP-ribose polymer repels negatively charged DNA, preventing unwanted recombination events at sites of DNA breakage ${ }^{135}$. Subsequent studies revealed that cells lacking XRCC1 accumulated more RAD51 foci, which are a marker of HRR, and $\gamma$-H2AX foci - a marker of DNA

\section{Box 1 | PARP cleavage and apoptosis}

A study in 1994 showed that poly(ADP-ribose) polymerase (PARP) can be cleaved during apoptosis ${ }^{126,127}$. Apoptosis is an energy-dependent programmed cell death pathway in which the activation of caspases in response to either death signalling molecules or excessive DNA damage leads to the breakdown of cell components (see figure). Apoptosis results in nuclear condensation and blebbing, and proinflammatory cellular contents are retained within membranes to prevent their extracellular release. The cleavage of PARP by activate caspases separates the DNA-binding domain from the catalytic domain, thereby preventing PARP activation. Whether this is to prevent PARP from consuming $\mathrm{NAD}^{+}$and/or limit poly(ADP-ribose) polymer formation is not clear and may depend on the cell or model system investigated. If PARP is not inactivated by cleavage, then there is a massive activation of PARP in response to DNA damage, resulting in $\mathrm{NAD}^{+}$and ATP depletion that may then cause necrosis or facilitate execution of an alternative cell death process known as parthanatos.

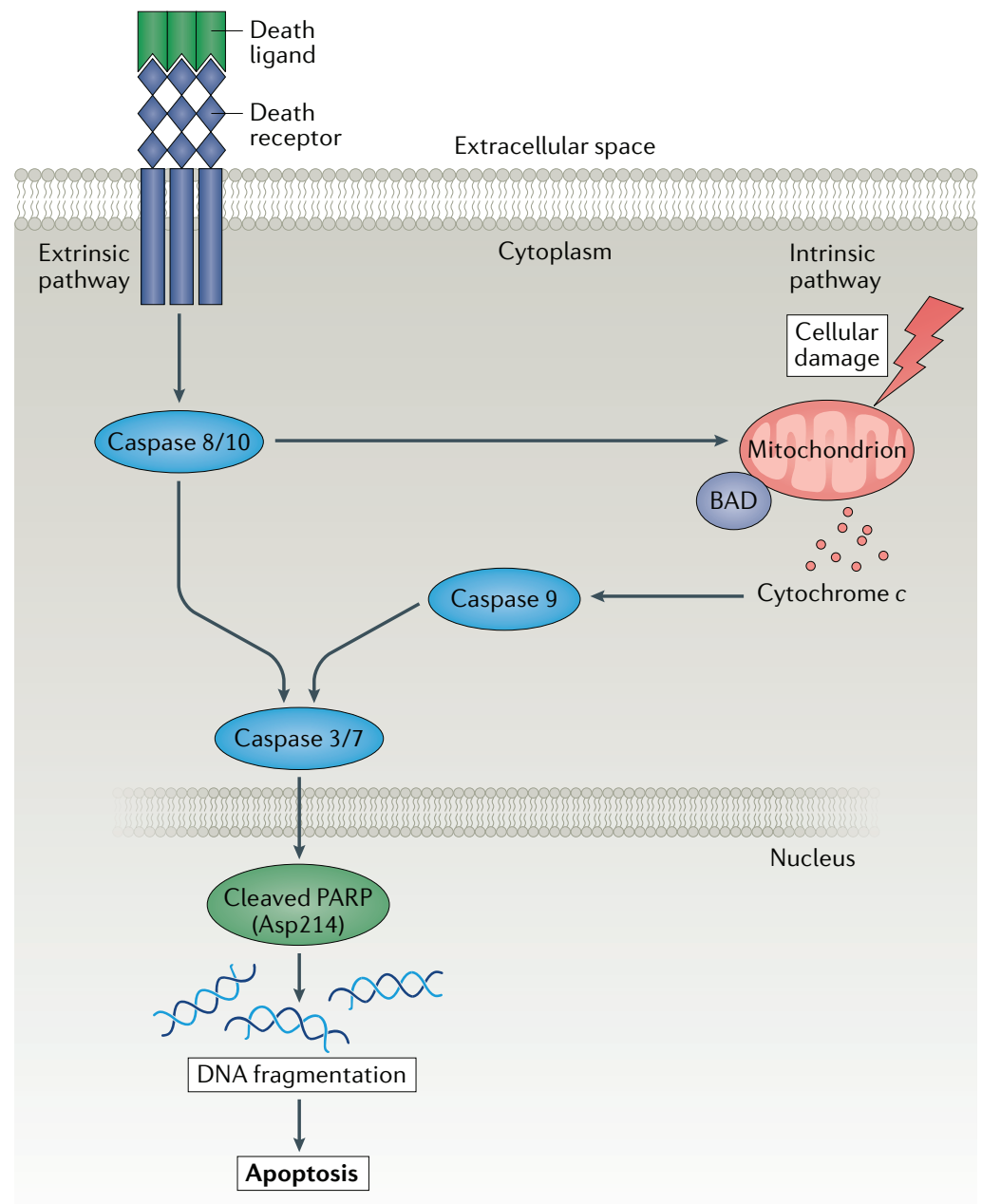

damage - suggesting that a failure to repair endogenous SSBs leads to replication fork collapse and activation of $\mathrm{HRR}^{136}$. This finding led to the hypothesis that cells lacking the ability for SSBR - for example, those lacking PARP1 or XRCC1 - are dependent on HRR for survival and that cells lacking HRR function, known as HRRdefective or homologous recombination-deficient cells, are dependent on PARP1 activity for survival. PARP inhibition in cells lacking HRR function could therefore lead to the death of replicating cells; that is, PARP inhibition and HRR defects are synthetically lethal (FIG. 3). This hypothesis was important for cancer therapy because of the role of the tumour suppressor genes $B R C A 1$ and BRCA2. BRCA1 and BRCA2 were first reported in the early 1990 s as breast cancer susceptibility genes, and by the beginning of the twenty-first century it was clear that they play key roles in $\mathrm{HRR}^{137}$. Two concurrent studies in 2005 demonstrated the synthetic lethality of two different PARP inhibitors in different $B R C A$-knockout and homologous recombination-deficient cell systems ${ }^{48,49}$. Importantly, both studies showed that a PARP inhibitor given to mice at non-toxic doses could shrink a $B R C A$-defective xenograft. This discovery represented a new paradigm in cancer therapy - exploiting a tumour-specific defect - and prompted the start of a period of intense activity focusing on the development of PARP inhibitors for cancer therapy. The first clinical data showing anticancer activity of PARP inhibitors in patients with $B R C A$ mutations appeared only 4 years after these early studies ${ }^{138}$. There was also a large increase in the number of preclinical studies focusing on PARP inhibitor cytotoxicity in cells and tumours with $B R C A$ mutations and/or a homologous recombination deficiency (HRD) phenotype (reviewed in REF. ${ }^{139}$ ), virtually all of which recapitulated the results of the 2005 studies described above.

Studies leading to regulatory approval. In the early 2000s, KuDOS Pharmaceuticals began developing PARP inhibitors and initiated clinical trials with olaparib as a single agent focused on patients with tumours and germ line $B R C A$ ( $g B R C A)$ mutations. A phase I trial initiated in 2005 was the first to show that olaparib suppressed the growth of tumours in patients with gBRCA mutations; in this study, approximately $50 \%$ of patients with tumours and gBRCA mutations who had been heavily pretreated with various other chemotherapeutic agents had a complete or partial response to olaparib, and most of these responding patients had ovarian cancer ${ }^{138}$. Now, several PARP inhibitors have shown success in clinical trials ${ }^{140-160}$, with some studies leading to regulatory approval; for a list of completed clinical trials on PARP inhibitors, see TABLE 2. Here and in the studies described below 'ovarian cancer' is used as a shorthand term for 'epithelial ovarian, fallopian tube and primary peritoneal cancer' because most of these tumours are now thought to arise from the fallopian tube rather than the ovary. At the end of 2014, olaparib was the first PARP inhibitor to be approved as a maintenance therapy for patients with gBRCA mutations and platinum-sensitive ovarian cancer. A randomized phase II trial ${ }^{145}$ in patients with platinum-sensitive ovarian cancer receiving olaparib 
a Chemosensitization and radiosensitization

\section{SSB}

- Temozolomide

- lonizing radiation/

reactive oxygen species

- Topoisomerase 1 poison

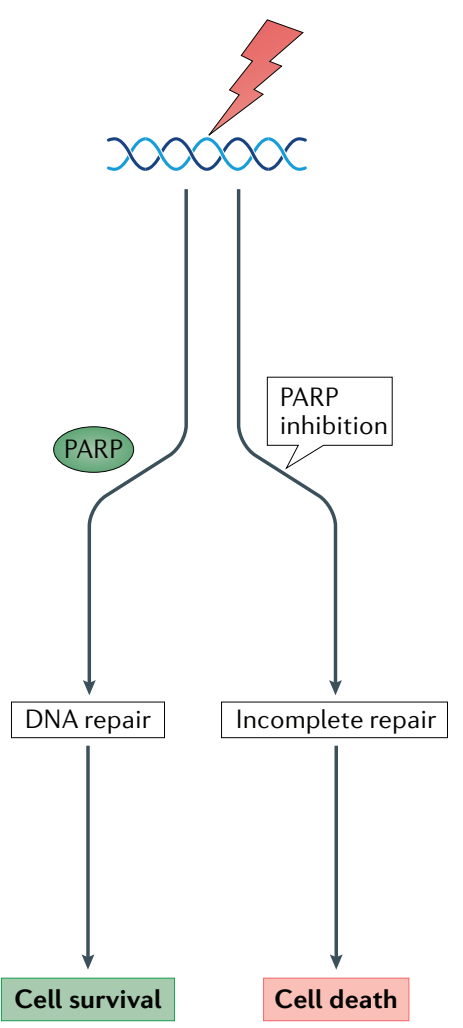

b Synthetic lethality

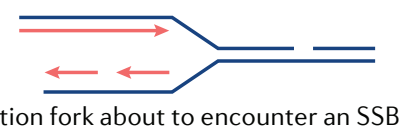

Replication fork about to encounter an SSB

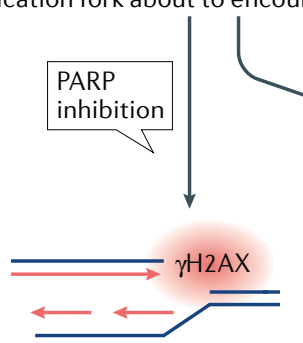

Fork collapse
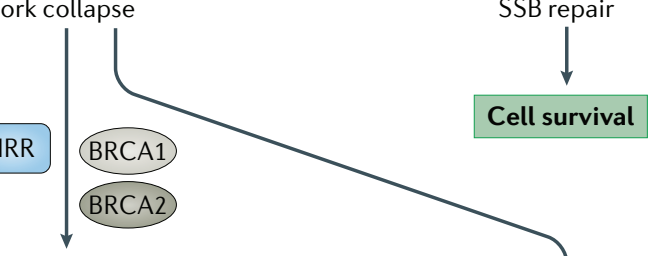

Strand invasion

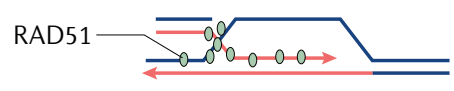

DNA synthesis

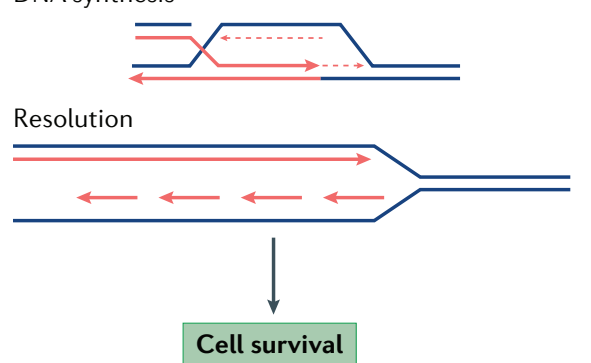

Fig. 3 | Molecular mechanisms of the anticancer effects of PARP inhibitors. a The molecular mode of action of poly(ADP-ribose) polymerase (PARP) inhibitors in chemosensitization and radiosensitization. DNA single-strand breaks (SSBs) induced by chemical agents or ionizing radiation may be repaired by PARP-dependent repair, resulting in tumour cell survival. Inhibition of PARP prevents DNA repair, resulting in cell death. $\mathbf{b}$ | The mechanism of action of PARP inhibitors in synthetic lethality in homologous recombination DNA repair (HRR)-deficient cells. Endogenously induced DNA SSBs are normally repaired by PARP-dependent SSB repair, resulting in cell survival. If PARP is inhibited, SSBs accumulate and cause replication fork collapse. This is usually repaired by HRR, which involves BRCA1, BRCA2 and several other proteins preparing the DNA ends for the loading of RAD51 onto the single-stranded DNA, subsequently enabling strand invasion into the complementary duplex as a template for DNA synthesis and high-fidelity DNA repair. In cases where homologous repair is disrupted — for example in BRCA-mutant cells — fork collapse cannot be repaired and the cell undergoes cell death. HRD, homologous recombination deficiency.

capsules orally at a dosage of $400 \mathrm{mg}$ daily showed that those with BRCA mutations had a significantly longer median progression-free survival (PFS) (11.2 months) than patients receiving placebo (4.3 months), and even in patients with wild-type $B R C A$, the PFS was extended to 7.4 months compared with 5.5 months for patients who received placebo.

Concurrent studies showed response to olaparib does not perfectly correlate with BRCA status ${ }^{140}$. The first study to probe the frequency of HRD in ovarian cancer used a functional assay, which showed that although only around $10-15 \%$ of ovarian cancers are in carriers of gBRCA mutations, $50-60 \%$ of tumours lack HRR function $^{141}$. Further studies confirmed this estimate through mutation screening ${ }^{142}$, confirming that gBRCA mutations substantially underestimate the frequency of HRD. Several methods can now be used to identify HRD, including screens for mutations in or epigenetic silencing of genes involved in HRR, copy number variations, signs of chromosomal instability such as loss of heterozygosity, large-scale transitions and telomeric allelic imbalance, and mutation signatures (reviewed in REFS ${ }^{143,144}$ ). As a consequence, commercial assays for determining HRD from Myriad Genetics and Foundation Medicine have been used as companion diagnostics in clinical trials that supported approval. A $300 \mathrm{mg}$ tablet formulation of olaparib (Lynparza; AstraZeneca) was approved for treatment of platinum-sensitive ovarian cancer regardless of BRCA status in 2017 and in 2018-2019 was approved as a first-line maintenance therapy for ovarian cancer.

The next PARP inhibitor to be approved was rucaparib (Rubraca; Clovis Oncology) in 2016, on the basis of a series of clinical trials ${ }^{146-150}$, which included a 
Table 2 | Selected completed clinical trials for PARP inhibitors in cancer

\begin{tabular}{|c|c|c|c|c|}
\hline Drug & $\begin{array}{l}\text { Trial phase (start year; } \\
\text { registration number; } \\
\text { acronym }^{\text {a) }}\end{array}$ & Cancer type & Key outcomes and comments & Refs \\
\hline \multicolumn{5}{|c|}{ First-in human and landmark trials } \\
\hline Rucaparib & I (2003; N/A) & $\begin{array}{l}\text { Solid tumours/ } \\
\text { melanoma }\end{array}$ & $\begin{array}{l}\text { First trial of a PARP inhibitor in cancer, in combination with temozolomide. } \\
\text { Established } 12 \mathrm{mg} \mathrm{m}^{-2} \text { as the RP2D in combination with full-dose } \\
\text { temozolomide }\end{array}$ & 130 \\
\hline Olaparib & I (2005; NCT00516373) & $\begin{array}{l}\text { Solid tumours, focusing } \\
\text { on patients with gBRCA } \\
\text { mutations }\end{array}$ & $\begin{array}{l}\text { First trial of a PARP inhibitor as a single agent in patients with BRCA } \\
\text { mutations. Responses in } 12 \text { of } 19 \text { heavily pretreated patients receiving } \\
200 \mathrm{mg} \text { twice daily }\end{array}$ & 138 \\
\hline Olaparib & II (2008; NCT00679783) & $\begin{array}{l}\text { High-grade ovarian } \\
\text { cancer and TNBC with } \\
\text { gBRCA mutations }\end{array}$ & $\begin{array}{l}\text { Identified a better response in ovarian cancer than in breast cancer and } \\
\text { that BRCA mutations were not the only discriminant associated with } \\
\text { platinum sensitivity }\end{array}$ & 140 \\
\hline \multicolumn{5}{|c|}{ Trials leading to regulatory approval } \\
\hline Olaparib & II (2008; NCT00753545) & $\begin{array}{l}\text { Relapsed } \\
\text { platinum-sensitive } \\
\text { ovarian cancer with } \\
\text { gBRCA mutations }\end{array}$ & $\begin{array}{l}\text { Patients with BRCA mutations had a longer median PFS in the olaparib } \\
\text { (capsules, } 400 \mathrm{mg} \text { daily) arm ( } 11.2 \text { months) than in the placebo arm } \\
\text { ( } 4.3 \text { months); patients with wild-type BRCA receiving olaparib had a PFS } \\
\text { of } 7.4 \text { months compared with } 5.5 \text { months for patients receiving placebo. } \\
\text { Data from this study supported FDA approval in } 2014 \text {, the first for a PARP } \\
\text { inhibitor }\end{array}$ & 145 \\
\hline Olaparib & $\begin{array}{l}\text { III (2013; NCT01874353; } \\
\text { SOLO-2) }\end{array}$ & $\begin{array}{l}\text { BRCA-mutated } \\
\text { platinum-sensitive } \\
\text { relapsed serous ovarian } \\
\text { cancer }\end{array}$ & $\begin{array}{l}\text { PFS in patients receiving olaparib was significantly longer ( } 19.1 \text { months) } \\
\text { than in those receiving placebo ( } 5.5 \text { months). Data from this study } \\
\text { supported FDA approval for a tablet formulation in } 2017\end{array}$ & 158 \\
\hline Olaparib & $\begin{array}{l}\text { III (2013; NCT01844986; } \\
\text { SOLO-1) }\end{array}$ & $\begin{array}{l}\text { BRCA-mutated } \\
\text { ovarian cancer after } \\
\text { platinum-based therapy }\end{array}$ & $\begin{array}{l}\text { Olaparib reduced the risk of disease progression or death by } 70 \% \\
\text { compared with placebo. Data from this study supported FDA approval } \\
\text { as first-line maintenance therapy in ovarian cancer in } 2018\end{array}$ & 159 \\
\hline Olaparib & III (2014; NCT02000622) & $\begin{array}{l}\text { BRCA-mutated breast } \\
\text { cancer }\end{array}$ & $\begin{array}{l}\text { Median PFS in the olaparib-treated patients was } 7 \text { months, significantly } \\
\text { longer than that of the standard therapy group ( } 4.2 \text { months). Data from } \\
\text { this study supported FDA approval in } 2018\end{array}$ & 160 \\
\hline Olaparib & $\begin{array}{l}\text { III (2014; NCT02184195; } \\
\text { POLO) }\end{array}$ & $\begin{array}{l}\text { BRCA-mutated } \\
\text { pancreatic cancer }\end{array}$ & $\begin{array}{l}\text { Median PFS in the olaparib-treated patients ( } 7.4 \text { months) was significantly } \\
\text { longer than in the placebo group ( } 3.8 \text { months). These data supported FDA } \\
\text { approval as first-line maintenance therapy in } 2019\end{array}$ & 157 \\
\hline Rucaparib & $\begin{array}{l}\text { I/II (2011; NCT01482715; } \\
\text { Study 10) }\end{array}$ & $\begin{array}{l}\text { Solid tumours/ } \\
\text { BRCA-mutated ovarian } \\
\text { cancer }\end{array}$ & $\begin{array}{l}\text { Dose escalation established a safe dose of } 600 \text { mg orally, twice daily. } \\
\text { Patients receiving rucaparib who had gBRCA mutations had an } \\
\text { investigator-assessed ORR of } 60 \% \text {. Together with ARIEL2, this study } \\
\text { supported accelerated FDA approval in } 2016\end{array}$ & 147 \\
\hline Rucaparib & $\begin{array}{l}\text { II (2013; NCT01891344; } \\
\text { ARIEL2) }\end{array}$ & $\begin{array}{l}\text { Platinum-sensitive, } \\
\text { relapsed, high-grade } \\
\text { epithelial ovarian, } \\
\text { fallopian tube or primary } \\
\text { peritoneal cancer }\end{array}$ & $\begin{array}{l}\text { Patients receiving rucaparib in a BRCA-mutation group had a median PFS } \\
\text { of } 12.8 \text { months, patients in a high-LOH group had a median PFS of } \\
5.7 \text { months and patients in a low-LOH group had a median PFS } \\
\text { of } 5.2 \text { months. Together with Study } 10 \text {, this supported FDA approval of } \\
\text { rucaparib alongside Foundation Medicine's companion diagnostic }\end{array}$ & 148 \\
\hline Rucaparib & $\begin{array}{l}\text { III (2014; NCT01968213; } \\
\text { ARIEL3) }\end{array}$ & $\begin{array}{l}\text { Platinum-sensitive, } \\
\text { relapsed, high-grade } \\
\text { epithelial ovarian, } \\
\text { fallopian tube or primary } \\
\text { peritoneal cancer plus a } \\
\text { predictive biomarker }\end{array}$ & $\begin{array}{l}\text { Patients treated with rucaparib had a significant increase in median PFS } \\
\text { ( } 10.8 \text { months) compared with patients who received placebo ( } 5.4 \text { months), } \\
\text { particularly in the subgroups of patients with BRCA mutations } \\
\text { (16.6 months) and HRD (13.6 months). Supported FDA approval in } 2018 \\
\text { for second-line therapy without the need for a companion diagnostic }\end{array}$ & 149,150 \\
\hline Niraparib & $\begin{array}{l}\text { III (2013; NCT01847274; } \\
\text { ENGOT-OV16/NOVA) }\end{array}$ & $\begin{array}{l}\text { Platinum-sensitive } \\
\text { ovarian cancer }\end{array}$ & $\begin{array}{l}\text { Niraparib extended the median PFS in patients with BRCA mutations } \\
\text { to } 21 \text { months compared with } 5.5 \text { months in the control arm. In patients } \\
\text { without BRCA mutations with or without an HRD signature, the median } \\
\text { PFS was } 12.3 \text { months and } 9.3 \text { months, respectively, in the niraparib arm } \\
\text { compared with } 3.9 \text { months in the placebo arm. Supported FDA approval } \\
\text { as maintenance therapy for platinum-sensitive ovarian cancer in } 2017\end{array}$ & 151 \\
\hline Niraparib & $\begin{array}{l}\text { II (2015; NCT02354586; } \\
\text { QUADRA) }\end{array}$ & Ovarian cancer & $\begin{array}{l}\text { Patients with tumour BRCA mutations with platinum-sensitive or } \\
\text { platinum-resistant disease had an ORR of } 39 \% \text { and } 29 \% \text {, respectively, and } \\
\text { those with a positive HRD test (Myriad myChoice CDx) result had an ORR } \\
\text { of } 24 \% \text {. These data supported FDA approval as maintenance therapy in } \\
\text { ovarian cancer after four previous chemotherapy regimens in } 2019\end{array}$ & 152 \\
\hline Talazoparib & $\begin{array}{l}\text { III (2013; NCT01945775; } \\
\text { EMBRC) }\end{array}$ & $\begin{array}{l}\text { gBRCA-mutant } \\
\text { HER2-negative locally } \\
\text { advanced or metastatic } \\
\text { breast cancer }\end{array}$ & $\begin{array}{l}\text { Patients receiving talazoparib had a median PFS of } 8.6 \text { months compared } \\
\text { with } 5.6 \text { months in the chemotherapy arm. These data supported FDA } \\
\text { approval of talazoparib in } 2018\end{array}$ & \\
\hline
\end{tabular}

Unless otherwise stated, poly(ADP-ribose) polymerase (PARP) inhibitors were evaluated as single agents. gBRCA, germline BRCA; HER2, human epidermal growth factor receptor 2; HRD, homologous recombination deficiency; $\mathrm{LOH}$, loss of heterozygosity; N/A, not applicable; ORR, overall response rate; PFS, progression-free survival; RP2D, recommended phase II dose; TNBC, triple-negative breast cancer. alf available. 
phase I/II dose escalation study known as Study 10 (REF. ${ }^{146}$ ), the phase II ARIEL2 trial $^{148,149}$ and the placebo-controlled phase III ARIEL3 trial ${ }^{150}$. These trials used Foundation Medicine's CDx HRD test to identify patients with homologous recombination-deficient tumours. There was an increase in PFS in all patients treated with rucaparib (10.8 months) compared with placebo (5.4 months). This increase was most marked in the cohort with BRCA mutations (16.6 months) and in those identified as having HRD with wild-type $B R C A$ (9.7 months) compared with individuals with no biomarker (6.7 months). As a result of the successful implementation of the CDx HRD test, it was co-approved with rucaparib as a companion diagnostic. Rucaparib was approved in 2018 by the FDA without the need for a companion diagnostic as maintenance therapy for platinum-sensitive ovarian cancer, with 'platinum sensitive' defined as a tumour that does not recur within 6 months or more following platinum-based therapy.

The PARP inhibitor niraparib (Zejula; Tesaro) was first approved in 2017 for platinum-sensitive ovarian cancer, regardless of $B R C A$ mutation status, on the basis of the ENGOT-OVA16/NOVA trial ${ }^{151}$. On the basis of results from the QUADRA trial, approval was subsequently extended to include patients who had undergone three or more prior chemotherapy regimens and were considered to have homologous recombination-deficient tumours, on the basis of results from $B R C A$ testing, results from Myriad's myChoice HRD test, or platinum sensitivity ${ }^{152}$.

Following the approval of the three aforementioned PARP inhibitors for treatment of ovarian cancer, studies on the next PARP inhibitor - talazoparib (Talzenna; Pfizer) - focused on breast cancer, with the EMBRACA trial ${ }^{153}$ leading to regulatory approval for the treatment of gBRCA-mutant, human epidermal growth factor receptor 2 (HER2)-negative breast cancer in 2018. Olaparib was also approved in 2019 for the treatment of HER2-negative locally advanced breast cancer in patients with $\mathrm{g} B R C A$ mutations. PARP inhibitors also showed efficacy in other tumour types associated with $B R C A$ mutations, with rucaparib and olaparib both being approved in 2020 for patients with BRCA1/BRCA2-mutated metastatic castration-resistant prostate cancer on the basis of the results of the TOPARP-B (NCT01682772) olaparib trial and the TRITON2 (NCT0295234) rucaparib trial. Niraparib has also shown compelling data for this indication in the GALAHAD (NCT02854436) trial ${ }^{156}$. Olaparib was approved in December 2019 for the maintenance of adult patients with deleterious or suspected deleterious gBRCA-mutated metastatic pancreatic adenocarcinoma on the basis of the results of the POLO trial ${ }^{157}$, in which the median PFS of the olaparib-treated group (7.4 months) was substantially longer than that of the placebo-treated group (3.8 months). Olaparib has also completed several additional phase III trials for use in ovarian and breast cancer ${ }^{158-160}$.

Ongoing clinical trials. Ongoing phase III trials of PARP inhibitors, including those studying the recently developed inhibitors pamiparib, fluzoparib and IMP4279 both as single agents and in various combinations, are summarized in TABLE 3. Despite entering clinical trials before niraparib or talazoparib, veliparib has failed to obtain regulatory approval, although it does have orphan drug status in the United States in combination with carboplatin and paclitaxel for treatment of non-smallcell lung cancer on the basis of a randomized phase II trial ${ }^{161}$. Veliparib is weaker than the approved PARP inhibitors and less potent at 'PARP trapping" ${ }^{162}$; this is likely to be a handicap in terms of single-agent activity but may prove an advantage in combination therapies. There are more than 100 studies with veliparib registered on ClinicalTrials.gov, most of which use veliparib in combination with genotoxic agents. Given that veliparib can cross the blood-brain barrier, one would predict it would be effective in patients with glioblastoma in combination with temozolomide and radiotherapy. Indeed, although this combination has been shown to be associated with haematological toxicity ${ }^{163}$, a phase I trial of veliparib in combination with whole brain radiotherapy in patients with brain metastases showed it was well tolerated and gave a better-than-predicted response ${ }^{164}$. The combination of veliparib and temozolomide was also well tolerated in paediatric patients with brain tumours ${ }^{165}$; however, in combination with radiotherapy, the temozolomide dose could not be escalated without toxicity ${ }^{166}$. So far, none of the trials with veliparib have progressed to registration.

The PARP inhibitors pamiparib and fluzoparib are relatively new, and it is not yet clear whether they hold advantages over the approved PARP inhibitors. Pamiparib, formerly BGB-290, was evaluated in a phase I dose escalation trial in patients with advanced solid tumours, which identified $80 \mathrm{mg}$ orally twice daily as the maximum tolerated dosage ${ }^{167}$. Pamiparib is reported to be selective for PARP1/2, with potent trapping activity and good brain penetration ${ }^{95,168}$. The only published clinical study on pamiparib is for its use in combination with an inhibitor of programmed cell death protein 1 (PD1); this combination was well tolerated by patients, with two complete responses and eight partial responses in a cohort of 49 patients with advanced solid tumours ${ }^{168}$. Preclinical data on fluzoparib suggest it is also a typical PARP1/2 inhibitor, with target inhibition potency comparable to that of olaparib, as it displays cytotoxicity in homologous recombination-deficient cells and when used in combination with temozolomide and radiotherapy ${ }^{96,169}$. The maximum tolerated dosage, in combination with apatinib and paclitaxel, was $80 \mathrm{mg}$ twice daily in patients with advanced gastric cancer, with evidence of response ${ }^{170}$.

For trials of PARP inhibitors in combination with cytotoxic anticancer agents, glioblastoma is an ideal target because the standard of care is temozolomide treatment and radiotherapy and there are extensive preclinical data showing that the cytotoxicity and antitumour activity of both of these treatments is increased in combination with a PARP inhibitor. However, the ability of a PARP inhibitor to cross the blood-brain barrier is likely to be a factor in the effective control of brain tumour growth, with the caveat that the blood-brain barrier at the tumour site may be different from that of 
Table 3 | Ongoing phase III clinical trials for PARP inhibitors in cancer

\begin{tabular}{|c|c|c|c|}
\hline $\begin{array}{l}\text { Trial start } \\
\text { date }\end{array}$ & Single agent or combination & Cancer type & $\begin{array}{l}\text { Registration } \\
\text { number }\end{array}$ \\
\hline \multicolumn{4}{|l|}{ Olaparib } \\
\hline Aug. 2013 & Combination with paclitaxel & Advanced gastric cancer & NCT01924533 \\
\hline Jan. 2014 & Single agent & BRCA-mutated, high-risk HER2-negative primary breast cancer & NCT02032823 \\
\hline Nov. 2014 & Single agent & $\begin{array}{l}\text { BRCA-mutated ovarian cancer after at least two prior platinum-based } \\
\text { treatments }\end{array}$ & NCT02282020 \\
\hline Nov. 2014 & Combination with pembrolizumab & Non-BRCA-mutated advanced epithelial ovarian cancer & NCT03740165 \\
\hline May 2015 & Combination with cediranib & $\begin{array}{l}\text { Recurrent platinum-sensitive ovarian, fallopian tube or primary } \\
\text { peritoneal cancer }\end{array}$ & NCT02446600 \\
\hline Jun. 2015 & Combination with bevacizumab & $\begin{array}{l}\text { High-grade serous or endometrioid ovarian, fallopian tube or peritoneal } \\
\text { cancer }\end{array}$ & NCT02477644 \\
\hline Jul. 2015 & Combination with cediranib & $\begin{array}{l}\text { Recurrent platinum-resistant or platinum-refractory ovarian, fallopian } \\
\text { tube or primary peritoneal cancer }\end{array}$ & NCT02502266 \\
\hline Jun. 2016 & Single agent & HER2-negative, BRCA1-like breast cancer & NCT02810743 \\
\hline Dec. 2016 & Single agent & Metastatic castration-resistant prostate cancer & NCT02987543 \\
\hline Apr. 2017 & Single agent & Non-mucinous epithelial ovarian cancer & NCT03106987 \\
\hline May 2017 & Combination with carboplatin and paclitaxel & Neoadjuvant treatment of TNBC and/or gBRCAm breast cancer & NCT03150576 \\
\hline Sep. 2017 & Single agent & Metastatic breast cancer & NCT03286842 \\
\hline Sep. 2017 & Single agent or combination with cediranib & Ovarian cancer & NCT03278717 \\
\hline Jan. 2018 & Single agent & Platinum-sensitive relapsed non-gBRCAm ovarian cancer & NCT03402841 \\
\hline May 2018 & Single agent & $\begin{array}{l}\text { Ovarian cancer-maintenance therapy after complete or partial } \\
\text { response to platinum-based chemotherapy }\end{array}$ & NCT03534453 \\
\hline Nov. 2018 & Combination with abiraterone & Metastatic castration-resistant prostate cancer & NCT03732820 \\
\hline Nov. 2018 & Combination with durvalumab, bevacizumab & Advanced ovarian cancer & NCT03737643 \\
\hline Feb. 2019 & Combination with pembrolizumab & Metastatic castration-resistant prostate cancer & NCT03834519 \\
\hline Jun. 2019 & Combination with pembrolizumab & First-line metastatic squamous non-small-cell lung cancer & NCT03976362 \\
\hline Jun. 2019 & Combination with pembrolizumab & Metastatic non-squamous non-small-cell lung cancer & NCT03976323 \\
\hline Dec. 2019 & Combination with pembrolizumab & TNBC & NCT04191135 \\
\hline \multicolumn{4}{|l|}{ Rucaparib } \\
\hline Aug. 2016 & Single agent & BRCA-mutant ovarian, fallopian tube or primary peritoneal cancer & NCT02855944 \\
\hline Nov. 2016 & Single agent & $\begin{array}{l}\text { Metastatic castration-resistant prostate cancer and homologous } \\
\text { recombination gene deficiency }\end{array}$ & NCT02975934 \\
\hline May 2018 & Combination with nivolumab & $\begin{array}{l}\text { Maintenance treatment following response to front-line } \\
\text { platinum-based chemotherapy }\end{array}$ & NCT03522246 \\
\hline \multicolumn{4}{|c|}{ Talazoparib } \\
\hline Jan. 2018 & Combination with enzalutamide & Metastatic castration-resistant prostate cancer & NCT03395197 \\
\hline \multicolumn{4}{|l|}{ Veliparib } \\
\hline Jan. 2014 & Combination with carboplatin & Early-stage TNBC & NCT02032277 \\
\hline Jun. 2014 & Combination with temozolomide & Newly diagnosed glioblastoma & NCT02152982 \\
\hline Jun. 2014 & Combination with carboplatin and paclitaxel & $\begin{array}{l}\text { HER2-negative metastatic or locally advanced unresectable } \\
\text { BRCA-associated breast cancer }\end{array}$ & NCT02163694 \\
\hline Oct. 2014 & Combination with carboplatin and paclitaxel & Metastatic or advanced non-squamous non-small-cell lung cancer & NCT02264990 \\
\hline Jun. 2015 & Combination with carboplatin and paclitaxel & $\begin{array}{l}\text { Stage III or IV, high-grade serous epithelial ovarian, fallopian tube or } \\
\text { primary peritoneal cancer }\end{array}$ & NCT02470585 \\
\hline \multicolumn{4}{|l|}{ Pamiparib } \\
\hline Feb. 2018 & Single agent & $\begin{array}{l}\text { Inoperable locally advanced or metastatic gastric cancer that } \\
\text { previously responded to platinum-based first-line chemotherapy }\end{array}$ & NCT03427814 \\
\hline \multicolumn{4}{|l|}{ Fluzoparib } \\
\hline Mar. 2019 & Single agent & Platinum-sensitive recurrent ovarian cancer - maintenance therapy & NCT03863860 \\
\hline \multicolumn{4}{|l|}{ IMP4297 } \\
\hline Nov. 2019 & Single agent & Ovarian cancer - maintenance therapy after first-line chemotherapy & NCT04169997 \\
\hline
\end{tabular}

gBRCAm, germline BRCA mutated; HER2, human epidermal growth factor receptor 2; PARP, poly(ADP-ribose) polymerase; TNBC, triple-negative breast cancer. 
healthy brain tissue. In most cases, brain penetration is determined by interaction with drug efflux ATP-binding cassette transporters ${ }^{171-173}$; olaparib, talazoparib and rucaparib are substrates for the ATP-binding cassette multidrug resistance transporters and are actively exported out of the cell, whereas niraparib and veliparib do not appear to be exported ${ }^{172}$.

PARP inhibitors have also been explored as modulators of immune signalling in cancers. The accumulation of DNA damage following PARP inhibition leads to leakage of damaged double-stranded DNA into the cytoplasm in both BRCA-mutant and wild-type cells, which can activate innate immune signalling through the cGAS-STING pathway, leading to increased expression and release of type I interferons ${ }^{174,175}$. Type I interferons drive the infiltration of cytotoxic $\mathrm{T}$ cells into the tumour; however, they can also suppress the $\mathrm{T}$ cell response by inducing expression of PD-L1 on the tumour surface, such that interfering with PD1/PD-L1 signalling is synergistic with PARP inhibition in vivo ${ }^{176}$. Several clinical studies of the combination of PARP inhibitors and immune checkpoint inhibitors have been initiated in recent years; it is too early to assess their overall outcome, but early results are promising ${ }^{177}$.

Factors affecting PARP inhibitor dosage. The approved dosages of the PARP inhibitors reflect their potencies for PARP inhibition and PARP trapping. The approved dosage of talazoparib, the most potent clinically used PARP inhibitor, is $1 \mathrm{mg}$ once daily, in comparison with much higher dosages for niraparib (300 mg once daily), olaparib (300 mg twice daily) and rucaparib (600 mg twice daily). However, differences in the recommended schedules and doses for niraparib, olaparib and rucaparib may be a reflection of pharmacokinetic data and safe or tolerable dose information rather than potency, as they seem to be similarly potent inhibitors of the catalytic activity of PARP1 in laboratory studies.

Side effects common to PARP inhibitors evaluated in clinical trials so far include fatigue, gastrointestinal effects such as nausea/vomiting, abdominal pain and diarrhoea, and haematological effects such as thrombocytopenia ${ }^{154,155}$. These effects are usually mild (grade 1 or 2) but can be more serious in rare cases ${ }^{154,155}$. Differences in side effect profiles between specific PARP inhibitors are likely to reflect differences in the dose and schedule, the half-life and the metabolic route by which the inhibitors are metabolized; for example, olaparib is metabolized by CYP3A4, rucaparib is metabolized by CYP2D6, and niraparib is metabolized by hepatic carboxylesterases. Side effect profiles may also differ because inhibitors have different specificities for PARP family enzymes or may interact with other $\mathrm{NAD}^{+}$-dependent enzymes. Niraparib is associated with thrombocytopenia, often necessitating dose reductions - particularly in women with low body weight - whereas with olaparib, rucaparib and talazoparib, anaemia is more likely to occur than thrombocytopenia ${ }^{154,155}$. An elevation in serum creatinine level has been observed following treatment with rucaparib and olaparib, likely caused by an effect on transporters rather than renal toxicity. Myelodysplastic syndrome and acute myeloid leukaemia have also been associated with PARP inhibitor therapy; however, as most patients treated with PARP inhibitors have also been treated with chemotherapy drugs known to be associated with myelodysplastic syndrome/acute myeloid leukaemia, it is difficult to attribute this entirely to the inhibition of PARP ${ }^{155}$.

Dose, schedule and toxicity are all important considerations when evaluating single-agent PARP inhibitor therapy against combination therapies involving conventional cytotoxic drugs or radiotherapy. Preclinical data demonstrate that only low doses of a PARP inhibitor and short administration schedules are needed to control tumour growth in combination with PARP inhibitor-relevant chemotherapy or radiotherapy, and higher doses can be profoundly toxic. In contrast, much higher doses and continuous schedules are required and tolerated for single agents in HRD xenograft models. The safe dosage of rucaparib in combination with temozolomide was determined as $12 \mathrm{mg} \mathrm{m}^{-2}$ given intravenously each day for a 5 -day period every 28 days ${ }^{130}$. By comparison, the approved dosage for rucaparib when used as a single agent was found to be $600 \mathrm{mg}$ orally twice daily to be taken continuously equivalent to roughly 20 times the safe dose when used in combination with temozolomide (based on $30 \%$ bioavailability and a body surface area of around $1.7 \mathrm{~m}^{2}$ ). When used in combination with carboplatin, a chemotherapy drug with a mechanism of action that does not influence PARP1 DNA-repair pathways as much as temozolomide, the safe dosage of rucaparib was found to be $240 \mathrm{mg}$ orally daily ${ }^{178}$ - only 2.5 -fold lower than when used as a single agent. The safe single agent dose of a PARP inhibitor is therefore likely to be at least an order of magnitude too high if used in combination with a chemotherapy drug that acts synergistically with the effects of PARP inhibitors. It is likely that high doses are needed for single-agent therapy as cells have an excess of PARP1 for repairing endogenous DNA damage, so PARP1 must be profoundly inhibited to render these physiological levels of DNA damage cytotoxic in homologous recombination-deficient cells. High doses are well tolerated in single-dose strategies as these high doses will not kill non-tumour, HRR-functional cells. When a massive amount of DNA damage is induced, for example, by temozolomide, there is no longer an overcapacity of PARP1 to repair this damage, so a more modest level of inhibition will render DNA breaks unrepairable in both tumour and non-tumour cells.

Counteracting the development of PARP inhibitor resistance. Mutations in cancer cells can render them intrinsically resistant to anticancer drugs, including PARP inhibitors. Cancer cells may also acquire resistance through genomic instability and tumour heterogeneity ${ }^{179}$. PARP inhibitor resistance can occur through four different mechanisms: reversal of the HRD phenotype, stabilization of the DNA replication fork, increasing PARylation activity and removal of the inhibitor from the cell by efflux transporters (reviewed in REF. ${ }^{155}$ ). Reversal of the HRD phenotype was the first resistance mechanism to be observed; the restoration of BRCA function can occur through the acquisition of 
secondary mutations in $B R C A$ that negate truncating mutations and restore an open reading frame. This effect was first observed in laboratory studies, then in clinical material from patients after platinum-based therapy ${ }^{180,181}$. Similar findings have been observed regarding reversion of deleterious mutations in RAD51C, RAD51D and PALB2 (REF. ${ }^{155}$ ). Subsequent studies showed that HRR can be restored by other means, most notably by the loss of TP53-binding protein 1 (53BP1). This protein acts in competition with BRCA1 at DNA DSBs, preventing end resection and causing the cell to make a futile attempt at NHEJ ${ }^{182,183}$. When NHEJ is prevented by deletion of 53BP1, HRR can proceed even in the absence of BRCA1. Similarly, loss of the mitotic spindle assembly checkpoint protein MAD2B, which acts downstream of 53BP1 to antagonize HRR, can also reverse the BRCA-related HRD phenotype ${ }^{184}$. Loss or inhibition of DNA-PKcs, a pivotal kinase in NHEJ, can also restore HRR function in BRCA-mutant cells ${ }^{185}$. Increasing replication fork stability by preventing excessive degradation by MRE11 can cause PARP inhibitor resistance even without restoring HRR function ${ }^{186}$. It is also possible that inactivation of PARG can restore PAR signalling and cause resistance to PARP inhibitors ${ }^{187}$. Loss of PARP1 may also confer PARP inhibitor resistance, as cytotoxicity may be related to PARP trapping rather than inhibition of PARP activity itself $^{162}$.

In an attempt to overcome PARP inhibitor resistance, work has focused on using therapeutic agents to induce the HRD phenotype and/or disrupt replication fork protection. These agents include phosphoinositide 3-kinase inhibitors and the tyrosine kinase inhibitor imatinib, which are reported to downregulate HRR and, in some cases, induce sensitivity to PARP inhibitors ${ }^{188,189}$; however, in some contexts they can induce protection from PARP inhibitors owing to cell cycle arrest ${ }^{190}$. The combination of PARP inhibitors and phosphoinositide 3-kinase inhibitors is currently under clinical evaluation in patients with gynaecological cancers and breast cancer (NCT01623349 and NCT03586661). Inhibitors of histone deacetylase and heat shock protein 90 (HSP90) have also been reported to compromise HRR by destabilizing key HRR proteins such as RAD51 and BRCA2 $\left(\right.$ REF $\left.^{191}\right)$. Currently, there is one trial of olaparib in combination with a histone deacetylase inhibitor (vorinostat) in breast cancer - registered but not yet recruiting (NCT03742245) - and one trial of olaparib and an HSP90 inhibitor (olanespib) in ovarian cancer (NCT02898207).

The DNA damage response can regulate both DNA repair and cell cycle arrest. The ATR-CHK1-WEE1 axis, activated in response to DNA damage, causes S-phase arrest through inhibition of cyclin-dependent kinase 2 (CDK2) and G2/M-phase arrest through inhibition of CDK1. The emerging role of cyclin-dependent kinases in HRR suggests that inhibitors of these cell cycle checkpoint kinases might be synthetically lethal with PARP inhibitors by inducing an HRD phenotype. A prototype small-molecule inhibitor of the serine/threonine-protein kinase ATR known as NU6027 was shown to increase rucaparib cytotoxicity in MCF7 cells and inhibit HRR function, in addition to attenuating cell cycle arrest ${ }^{192}$.
Several studies have since shown that ATR, CHK1 and WEE1 inhibitors can sensitize $B R C A$-wild-type and PARP inhibitor-resistant cells to PARP inhibitors $^{193-195}$. There are currently several ongoing clinical trials of PARP inhibitors in combination with ATR inhibitors (NCT02723864, NCT03462342, NCT03787680, NCT04065269, NCT04149145, NCT03682289, NCT03022409 and NCT03740893) and CHK1 inhibitors (NCT03057145). In addition, CDK1 inhibitors have been shown to induce the HRD phenotype and confer sensitivity to PARP inhibitors preclinically ${ }^{196}$ and are undergoing clinical evaluation (NCT01434316).

\section{PARP inhibition beyond oncology}

Pathophysiological processes that lead to PARP activation. PARP1 is constitutively expressed in most cells and has a basal activity, as evidenced by PAR formation in normal cells. This basal activity is maintained by the physiological occurrence of DNA strand breakage, likely generated by the endogenous production of oxidants and free radicals as a result of biochemical processes such as mitochondrial electron transfer. It was a surprise when PARP activity was found to be elevated in various non-oncological disease condition $s^{32,33,39,42}$ because until the 1990s it was not commonly accepted that pathophysiological states could produce genotoxic amounts of oxidants or free radicals. PARP activation, characterized by increased PAR accumulation, has now been implicated in a range of pathological conditions, including ischaemia, ischaemia-reperfusion injury, inflammation, neurological injury, vascular disease and diabetes mellitus. In these conditions, DNA-damaging oxidants and free radicals are produced by a variety of sources, including NADPH oxidases, xanthine oxidase, mitochondria and tissue-infiltrating immune cells (reviewed in REFS ${ }^{197,198}$ ).

PARP mediates a range of pathological mechanisms. The use of PARP inhibitors and Parp1-knockout mice has revealed that PARP activation plays an active role in cell dysfunction, organ dysfunction and dysregulated inflammatory and immune responses (reviewed in REFS $\left.{ }^{199-204}\right)$. PARP inhibition therefore represents a potential treatment for a range of diseases caused by these underlying conditions. Early studies showed that PARP overactivation - caused by excessive DNA damage induced by reactive oxygen species - can drive a cellular energetic deficit, inducing cell necrosis and organ dysfunction in various diseases, including stroke, myocardial ischaemia-reperfusion injury, and various forms of critical illness ${ }^{200,205,206}$ (FIG. 4a). Subsequent studies revealed multiple additional mechanisms by which PARP activation can drive pathological states. Free PAR can exit the nucleus and diffuse to various cellular targets. One of the consequences of this process is the mitochondrial release of apoptosis-inducing factor 1 (AIF), which, in turn, induces nuclear DNA fragmentation through a distinct form of cell death called 'parthanatos' that is relevant in the pathogenesis of stroke, neuroinflammation and neurodegeneration ${ }^{206}$ (FIG. 4b). Free PAR also mediates other pathophysiological processes; for example, PAR binding to $a$-synuclein renders it more neurotoxic 
in neurodegenerative processes ${ }^{59}$, and both intracellular and extracellular PAR can drive atherosclerosis by promoting vascular calcification ${ }^{61}$ (FIG. 4C).

PARP activation can drive the pathogenesis of various non-oncological diseases through its role as the regulator of signal transduction and gene transcription. PARP regulates the activation of various signalling pathways, including the nuclear factor- $\kappa \mathrm{B}$ and JUN amino-terminal kinase pathways. Studies in various disease models of local and systemic inflammation and autoimmune diseases (arthritis and multiple sclerosis) have demonstrated that PARP inhibitors, or PARP1 deficiency, can suppress the expression of adhesion molecules such as ICAM1, proinflammatory cytokines such as tumour necrosis factor (TNF) and chemokines such as macrophage inflammatory protein $1 \alpha^{201-203}$. It is likely that, in vivo, cell dysfunction and proinflammatory signalling processes form positive-feedback cycles of pathogenesis (reviewed in REF. ${ }^{201}$ ) (FIG. 4d). PARP acts as a global regulator of gene expression by modulating chromatin folding (FIC. 4e), and similarly, PARP1 interacts with various epigenetic mechanisms to modulate gene expression, including inhibiting the DNA methyltransferase DNMT1, which in turn suppresses DNA methylation (FIG. 4f). PARP activation and direct or indirect PARylation can mediate pathogenic processes by unfavourably regulating the activity of various kinase cascades, including those mediated by AKT/glycogen synthase kinase $3 \beta$, mitogen-activated protein kinases and various protein kinase $\mathrm{C}$ isoforms ${ }^{207}$. In many cardiovascular disease models, pharmacological PARP inhibition induces cytoprotective AKT activation, and this effect underlies some of the beneficial effects of PARP inhibitors $^{44,207}$. PARP1 PARylates ataxia telangiectasia mutated (ATM), preventing it from interacting with the protein nuclear factor- $\kappa B$ essential modulator (NEMO). PARP1 inhibition suppresses PARylation of ATM in the nuclear compartment, allowing ATM to form a complex with NEMO that exits the nucleus and combines in the cytosol with mTOR and AKT. Formation of this complex activates the phosphorylation of AKT, which produces a cytoprotective response through the induction of AKT-mediated survival pathways ${ }^{208}$ (FIG. 4g).

Clinical trials of PARP inhibitors for non-oncological diseases. Studies in the late 1990s demonstrated that pharmacological inhibition of PARP may exert cardioprotective effects; for example, a reduction in infarct size and/or improvements in cardiac contractility and cardiac remodelling in animal models of myocardial infarction, cardiopulmonary bypass and chronic heart failure ${ }^{33,209}$. Subsequent studies in preclinical samples $^{210}$ and specimens from patients with myocardial infarction ${ }^{211}$ confirmed that PARP activation occurs in the heart and in circulating leukocytes after myocardial reperfusion. The third-generation PARP inhibitor INO-1001 reduced infarct size and improved cardiac function in preclinical models of myocardial ischaemiareperfusion ${ }^{212-215}$ and exerted beneficial effects in models of cell and tissue injury, including improvement of neurological function in models of neuroinjury and improved cardiac, vascular and renal function in models of diabetic complications ${ }^{73,216-220}$. As a result of these studies, INO-1001 became the first PARP inhibitor to enter human clinical trials in healthy human volunteers in 2003 and patients with myocardial infarction in 2004 (REF. ${ }^{221}$ ). The 2004 trial showed that PARP inhibition may suppress inflammation in patients with myocardial infarction, as measured by plasma $\mathrm{C}$-reactive protein and IL-6 levels ${ }^{221}$; however, the development of INO1001 for the treatment of cardiovascular disease was not pursued further, and its development as a cancer treatment did not progress beyond an initial safety study in patients with melanoma ${ }^{222}$.

There are now renewed efforts to develop PARP inhibitors as cytoprotective agents for various nononcological diseases. On the basis of preclinical studies in vitro and in murine models ${ }^{97,223}$, amelparib (formerly JPI-289) entered clinical trials in 2013. Safety and tolerability trials in healthy human volunteers (NCT01983358 and NCT02396069) were completed in 2015 , and a multicentre efficacy and safety trial in patients with stroke began in 2017 and is ongoing (NCT03062397). Preclinical data indicated that amelparib treatment is efficacious in reducing infarct size even when treatment with the inhibitor is delayed for 12 hours after stroke onset ${ }^{224}$. Although the results of the multicentre stroke trial have not yet been disclosed, an ex vivo study in which leukocytes from patients with stroke were treated with $1-10 \mu \mathrm{M}$ amelparib showed that the PARP inhibitor increases regulatory $\mathrm{T}$ cell expansion in vitro, reduces the production of TNF and IFN $\gamma$, and increases the production of the anti-inflammatory cytokine IL-10 (REF.224). Mitobridge, a Boston-based biotech company, has disclosed the results of in vitro and in vivo studies with a novel, non-genotoxic PARP inhibitor, showing that the inhibitor has nanomolar potency and improves organ function in a rat model of renal ischaemia-reperfusion ${ }^{225}$.

Future potential for PARP inhibitor repurposing. To date, all clinically approved PARP inhibitors have primarily been developed and preclinically evaluated for their anticancer effects in the context of cancer cell lines and tumour-bearing mice. However, these drugs could be repurposed for non-oncological indications (reviewed in REFS ${ }^{226-228}$ ). Preclinical studies in various experimental models, including stroke, neuroinjury, acute lung injury and circulatory shock, demonstrate the efficacy of the clinically approved PARP inhibitors ${ }^{229-254}$ (summarized in TABLE 4).

One important common feature of these studies is that the in vivo doses or the in vitro concentrations of the PARP inhibitors that demonstrate efficacy tend to be an order of magnitude lower than those used in preclinical oncology models (reviewed in REF. 227 ). One possible explanation for this difference is that for the inhibition of DNA repair, a complete or near-complete inhibition of all PARP1 activity is required, while for cytoprotective effects such as the restoration of cellular NAD levels, the attenuation of free PAR formation or activation of cytoprotective AKT pathways, partial inhibition of PARP1 may be sufficient. This suggests that the effective doses of the PARP inhibitors in repurposing indications will 
a Regulation of NAD+ and ATP levels

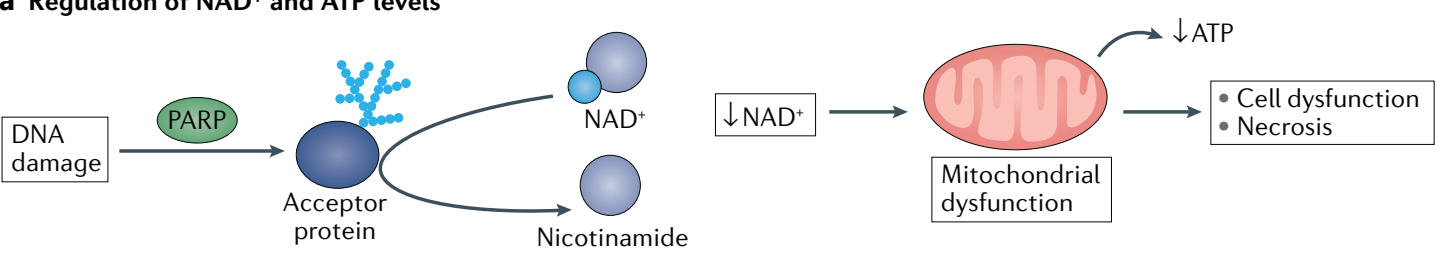

\begin{tabular}{|l|}
\hline PARP inhibitors \\
- Preserve NAD ${ }^{+}$and \\
ATP levels \\
- Maintain cell \\
function \\
- Protect against \\
necrosis
\end{tabular}

\section{b Signal transduction}
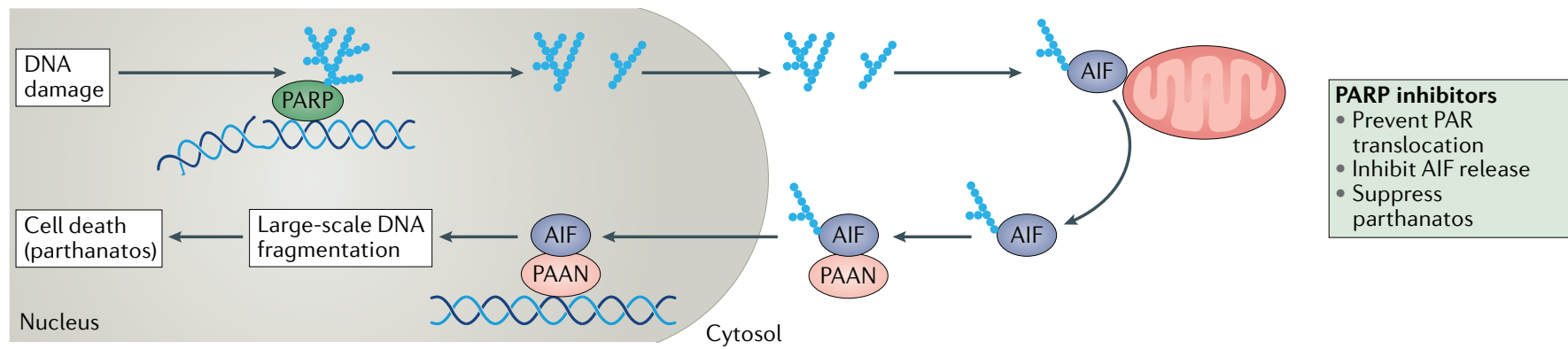

Cytosol

c Free PAR polymer regulation
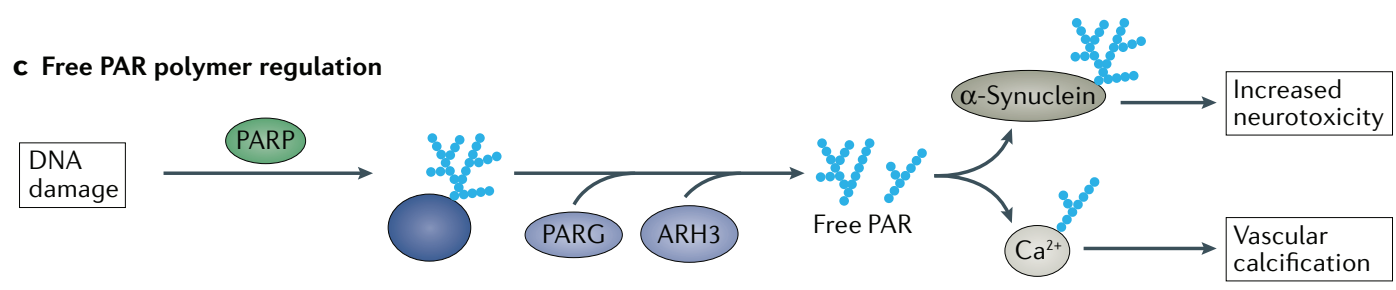

PARP inhibitors
- Prevent PAR
production
- Inhibit PAR-related
downstream
pathophysiological
events

d Transcriptional regulation

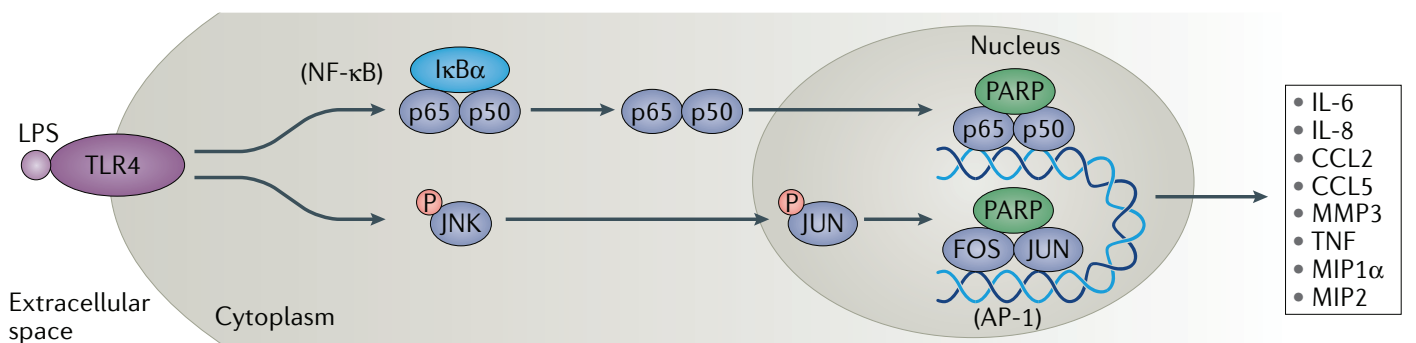

PARP inhibitors
- Globally regulate
gene expression
- Suppress the
production of many
proinflammatory
cytokines and
chemokines

space

\section{e Modulation of chromatin folding}

\section{PARP inhibitors}

- Reduce expression of genes contributing to pathological phenotype

\section{f Modulation of DNA methylation}

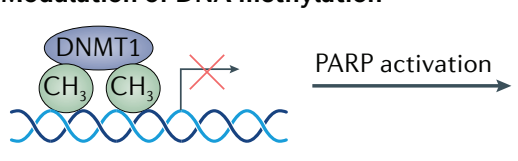

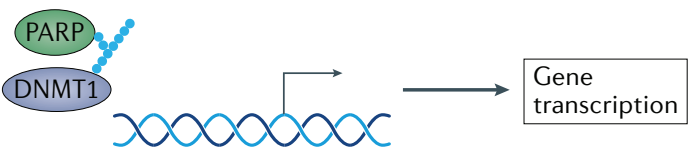

PARP inhibitors

- Reduce expression of genes contributing to pathological phenotype

g Regulation of the AKT survival pathway

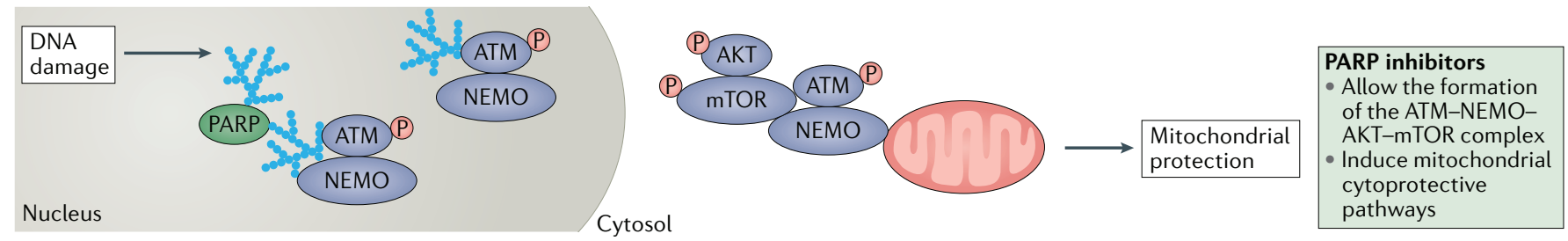


4 Fig. 4 | PARP inhibition in treating non-oncological diseases. a | In non-oncological diseases such as reperfusion injury, shock and inflammation, oxidants and free radicals produce DNA single-strand breaks, which activate poly(ADP-ribose) polymerase (PARP) The subsequent cellular energetic deficiency caused by PARP activation produces cell dysfunction and can promote cell death through necrosis, which mediates disorders associated with neuronal or myocardial cell death or vascular dysfunction. PARP inhibitors suppress these processes by attenuating cellular energetic deficit (discussed in REFS $^{77,78,199,201}$ ). b | Activation of PARP results in poly(ADP-ribosyl)ation (PARylation) of acceptor proteins, including PARP itself. Some poly(ADP-ribose) (PAR) translocates to the cytosolic compartment and binds to mitochondrial receptors, resulting in the release of apoptosis-inducing factor 1 (AIF), which diffuses to the nucleus and promotes large-scale nuclear fragmentation and cell death through a process known as parthanatos. The PARP1-dependent AIF-associated nuclease (PAAN) involved in DNA fragmentation was recently identified as macrophage migration inhibitory factor (MIF). PARP inhibitors prevent PARylation and subsequent pathophysiological events (further discussed in REF. $\left.{ }^{206}\right)$. c | Free PAR can post-translationally modify intracellular and extracellular targets, mediating pathophysiological processes such as $\alpha$-synuclein cytotoxicity in the context of chronic neurodegeneration and vascular calcification in the context of vascular injury. PARP inhibitors prevent PARylation and reduce free PAR formation (further discussed in REFS $\left.^{52,59,61,206}\right)$. d | PARP acts as a transcriptional co-regulator of genes involved in various cellular processes, including genes encoding proinflammatory cytokines and

chemokines that are regulated by the JUN amino-terminal kinase (JNK) and nuclear factor- $\kappa B(N F-\kappa B)$ pathways. Inhibition of PARP can therefore suppress the production of proinflammatory cytokines that are linked to local inflammatory conditions such as arthritis and systemic inflammatory conditions such as septic shock. e|PARylation of histones can regulate their conformation and their interaction with the DNA, loosening the chromatin and allowing transcription of otherwise silenced genes. Inhibition of PARP prevents histone PARylation and access of the gene transcription machinery to the DNA. f PARP can act as an epigenetic regulator through the modulation of DNMT1, a major maintenance methyltransferase. PARP overactivation can lead to the formation of PARP1-DNMT1 complexes through linking of the two proteins by PAR chains; this inhibits the DNA-methylating activity of DNMT1, leading to an increase in gene expression. PARP inhibitors prevent the sequestration of DNMT1, thereby allowing it to methylate DNA and inhibit gene expression. By affecting the processes depicted in parts $\mathbf{d}-\mathbf{f}$, PARP inhibition can suppress proinflammatory cytokine production and thereby exerts beneficial effects in various local and systemic inflammatory diseases; these processes are further discussed in $\mathrm{REFS}^{67,68,75,201,216} \cdot \mathbf{g}$ | PARP prevents interactions between the proteins phosphorylated ataxia telangiectasia mutated (ATM) and nuclear factor- $\kappa$ B essential modulator (NEMO). Inhibition of PARP facilitates the translocation of phosphorylated ATM-NEMO from the nucleus to the cytoplasm and formation of the cytoprotective phosphorylated ATM-NEMO-AKT-mechanistic target of rapamycin (mTOR) signalosome, which activates various cell survival pathways. These processes are further discussed in REFS ${ }^{208,286}$. ARH3, ADP-ribosylhydrolase 3; LPS, bacterial lipopolysaccharide; MIP1 $\alpha$, macrophage inflammatory protein 1a; PARG, poly(ADP-ribose) glycohydrolase; TLR, Toll-like receptor 4; TNF, tumour necrosis factor.

be lower than those used for single-agent treatment of cancer.

Repurposing of PARP inhibitors for non-oncological indications must take into account a number of factors. As discussed in REF. ${ }^{227}$, the indications for which repurposing is most promising are those where the preclinical evidence for the pathogenic role of PARP1 is clear, the disease is severe enough and lacks currently available therapies such that novel experimental approaches are justified, and the disease is such that adequately designed and powered trials are practically feasible. Furthermore, to reduce the risk of prolonged exposure to a PARP inhibitor, which could interfere with the maintenance of genomic integrity, indications for which the inhibitor could be administered for a short duration are preferable. Such indications include forms of acute neuroinjury such as stroke and acute neurotrauma, and critical illnesses such as septic shock and acute lung injury.

The risk of PARP inhibitor-associated impairment of DNA repair is mitigated by the fact that patients in the targeted groups do not have mutations that impair HRR and are not receiving genotoxic drugs. Indeed, it is conceivable that such mutations and the concomitant use of genotoxic drugs would be possible counterindications for the use of PARP inhibitors in non-oncological diseases. In addition, the low dose of the inhibitor compared with oncological doses would be expected to produce only partial inhibition of PARP activity for a relatively short time. One key aspect of PARP-mediated pathogenic mechanisms is that they preferentially affect males; in premenopausal females, the protective effect of PARP inhibitors is less pronounced or non-existent ${ }^{245,255-257}$. The underlying reason is not clear, but is probably related to the modulation of PARP activation by endogenous androgens or oestrogens ${ }^{258}$. Consequently, repurposing clinical trials should also consider sex differences and build this factor into the trial design prospectively.

\section{Other PARP family members as targets}

Although approximately $90 \%$ of cellular PAR formation is catalysed by PARP1 (REF. ${ }^{29}$ ), several other PARP family members exert important biological functions and may serve as drug targets. We focus here on those isoforms that can catalyse significant PARylation reactions (as opposed to mono(ADP-ribosyl)ation (MARylation) reactions), in particular PARP2, PARP5A and PARP5B. The therapeutic potential of inhibiting various MARylating enzymes, such as PARP14, has been reviewed elsewhere ${ }^{259,260}$.

PARP2 was first identified after it was found that cells from Parp1-knockout mice were capable of synthesizing PAR after DNA damage ${ }^{35}$. PARP2 is structurally similar to PARP1, sharing more than $60 \%$ sequence homology in its catalytic domain with that of PARP1, although it lacks zinc-finger motifs at its amino terminus ${ }^{46}$. Like PARP1, it is activated by binding to DNA breaks through its tryptophan-glycine-arginine (WGR)-rich domain, and can PARylate itself and histones, leading to the recruitment of XRCC1 and other base excision repair proteins, thereby promoting DNA repair ${ }^{261,262}$. PARP1 and PARP2 can compensate for the deletion of each other; indeed, deletion of both PARP1 and PARP2 results in embryonic lethality, highlighting the importance of the SSBR pathway for viability ${ }^{45}$.

It is difficult to disentangle the differential effects of inhibitors on PARP1 and PARP2, and most inhibitors have been found to be more promiscuous than first thought, as reviewed in REFS ${ }^{263-266}$. Several groups have attempted to make PARP1-selective or PARP2-selective inhibitors ${ }^{267}$ (reviewed in REF. ${ }^{264}$ ). There is some discrepancy between publications regarding the potency and selectivity of PARP inhibitors, perhaps reflecting the use of different methods and difficulty in translating in vitro data to in vivo models. For example, talazoparib had similar PARP1 inhibitory potency to olaparib when assayed in a cell-free, in vitro microplate assay that uses streptavidin to detect the incorporation of biotinylated $\mathrm{NAD}^{+}$into polymers ${ }^{266}$, but in vivo and clinical studies indicate that talazoparib is an order of magnitude more potent than other clinically approved inhibitors, possibly because of talazoparib's greater PARP 'trapping' potency ${ }^{162}$. 
Table 4 | Clinically approved PARP inhibitors in models of non-oncological diseases

\begin{tabular}{|c|c|c|c|c|}
\hline Experimental model & Disease modelled & $\begin{array}{l}\text { Drug (concentration } \\
\text { or dose/dosage) }\end{array}$ & Effects & Refs \\
\hline \multicolumn{5}{|l|}{ In vitro } \\
\hline $\begin{array}{l}\text { Endothelial cells subjected to high } \\
\text { glucose concentrations }\end{array}$ & $\begin{array}{l}\text { Diabetic vascular } \\
\text { dysfunction }\end{array}$ & Veliparib $(5 \mu \mathrm{M})$ & Protection against DNA fragmentation & 229 \\
\hline AML12 hepatocytes & Fatty liver disease & Olaparib (100nM) & $\begin{array}{l}\text { Increased cellular bioenergetics, induction } \\
\text { of mitochondrial biogenesis and induction of } \\
\text { lipolysis-related genes }\end{array}$ & 230 \\
\hline $\begin{array}{l}\text { C2C12 myotubes subjected to } \\
\text { oxidative stress }\end{array}$ & $\begin{array}{l}\text { Oxidative stress-related } \\
\text { diseases }\end{array}$ & $\begin{array}{l}\text { Olaparib or veliparib } \\
(100 \mathrm{nM})\end{array}$ & Maintenance of cellular bioenergetics & 231 \\
\hline $\begin{array}{l}\text { Human } C D 4^{+} T \text { cells stimulated with } \\
\text { anti-CD3 and anti-CD28 }\end{array}$ & Asthma, inflammation & Olaparib $(1-5 \mu \mathrm{M})$ & $\begin{array}{l}\text { Beneficial modulation of cytokine responses and } \\
\text { T cell subpopulations }\end{array}$ & 232 \\
\hline $\begin{array}{l}\text { Cultured human neurons subjected to } \\
\text { NMDA or oxygen/glucose deprivation }\end{array}$ & $\begin{array}{l}\text { Neurotoxicity, } \\
\text { neurodegeneration }\end{array}$ & Olaparib $(2 \mu \mathrm{M})$ & Neuroprotection & 233 \\
\hline $\begin{array}{l}\text { Monocytes in co-culture with } \\
\text { endothelial cells }\end{array}$ & $\begin{array}{l}\text { Neuroinflammation, } \\
\text { stroke }\end{array}$ & $\begin{array}{l}\text { Olaparib or } \\
\text { talazoparib }(10 \mu \mathrm{M})\end{array}$ & Reduced cell adhesion and migration & 234 \\
\hline ATM-deficient primary neurons & Ataxia telangiectasia & Olaparib (500nM) & $\begin{array}{l}\text { Reduced oxidant production, improved cellular } \\
\text { bioenergetics }\end{array}$ & 226 \\
\hline $\begin{array}{l}\text { Retinal explants from the rd } 1 \text { or rd } 10 \\
\text { mouse }\end{array}$ & Retinitis pigmentosa & Olaparib $(0.1-10 \mu \mathrm{M})$ & $\begin{array}{l}\text { Rescue of photoreceptors and protection } \\
\text { against cell death }\end{array}$ & 236,237 \\
\hline $\begin{array}{l}\text { ARPE- } 19 \text { cells subjected to oxidative } \\
\text { stress }\end{array}$ & Retinal degeneration & Olaparib $(10 \mu \mathrm{M})$ & $\begin{array}{l}\text { Protection against cell death and regulation of } \\
\text { inflammation-related genes }\end{array}$ & 238,239 \\
\hline $\begin{array}{l}\mathrm{C} 2 \mathrm{C} 12 \text { myotubes subjected to } \\
\text { oxidative stress }\end{array}$ & Myopathies & $\begin{array}{l}\text { Olaparib or veliparib } \\
(100 \mathrm{nM})\end{array}$ & Maintenance of cellular bioenergetics & 240 \\
\hline H9c2 cells subjected to oxidative stress & Myocardial infarction & Olaparib $(10 \mu \mathrm{M})$ & $\begin{array}{l}\text { Protection against cell death and mitochondrial } \\
\text { dysfunction }\end{array}$ & 241 \\
\hline COS-2 cells subjected to arsenite & ALS & Veliparib $(1-5 \mu \mathrm{M})$ & Inhibition of stress granule formation & 242 \\
\hline $\begin{array}{l}\text { Mixed spinal-cord cultures isolated } \\
\text { from rat embryos subjected to TDP43 } \\
\text { overexpression }\end{array}$ & ALS & Veliparib $(10 \mu \mathrm{M})$ & Protection against neuronal degeneration & 242 \\
\hline $\begin{array}{l}\text { Primary cortical neurons subjected to } \\
\text { oxygen/glucose deprivation }\end{array}$ & $\begin{array}{l}\text { Neurotoxicity, } \\
\text { neurodegeneration }\end{array}$ & Veliparib $(10 \mu \mathrm{M})$ & $\begin{array}{l}\text { Neuroprotection and maintenance of } \mathrm{NAD}^{+} \\
\text {levels }\end{array}$ & 243 \\
\hline $\begin{array}{l}\text { Rat hippocampal-entorhinal cortical } \\
\text { slices exposed to ethanol }\end{array}$ & Ethanol neurotoxicity & $\begin{array}{l}\text { Olaparib or veliparib } \\
(1 \mu \mathrm{M})\end{array}$ & $\begin{array}{l}\text { Neuroprotection and prevention of HMGB1 } \\
\text { release }\end{array}$ & 244 \\
\hline U937 cells subjected to oxidative stress & $\begin{array}{l}\text { Oxidative stress-related } \\
\text { diseases }\end{array}$ & Olaparib $(1-30 \mu \mathrm{M})$ & $\begin{array}{l}\text { Protection against cell death and maintenance } \\
\text { of cellular bioenergetics }\end{array}$ & 245 \\
\hline $\begin{array}{l}\text { HPDE cells subjected to oxidative } \\
\text { stress }\end{array}$ & Pancreatitis & Olaparib $(1-30 \mu \mathrm{M})$ & $\begin{array}{l}\text { Protection against cell death and maintenance } \\
\text { of cellular bioenergetics }\end{array}$ & 246 \\
\hline $\begin{array}{l}\text { Primary mouse cortical neurons } \\
\text { subjected to } \alpha \text {-synuclein }\end{array}$ & $\begin{array}{l}\text { Neurodegenerative } \\
\text { diseases }\end{array}$ & $\begin{array}{l}\text { Veliparib, rucaparib or } \\
\text { talazoparib }(1 \mu \mathrm{M})\end{array}$ & Protection against cell death & 59 \\
\hline $\begin{array}{l}\mathrm{HL}-1 \text { cardiomyocytes or isolated rat } \\
\text { atrial cardiomyocytes subjected to } \\
\text { tachypacing }\end{array}$ & $\begin{array}{l}\text { Atrial fibrillation, } \\
\text { cardiac arrhythmias }\end{array}$ & $\begin{array}{l}\text { Olaparib }(5-20 \mu \mathrm{M}) \text { or } \\
\text { veliparib }(5-40 \mu \mathrm{M})\end{array}$ & $\begin{array}{l}\text { Protection against } \mathrm{NAD}^{+} \text {depletion and oxidative } \\
\text { protein/DNA damage, prevention of channel } \\
\text { remodelling and improved electrophysiology }\end{array}$ & 247 \\
\hline $\begin{array}{l}\text { hVSMCs or MC3T3 cells subjected to } \\
\text { calcification-inducing conditions }\end{array}$ & $\begin{array}{l}\text { Vascular calcification, } \\
\text { atherosclerosis }\end{array}$ & $\begin{array}{l}\text { Olaparib, veliparib or } \\
\text { rucaparib }(3 \mu \mathrm{M})\end{array}$ & Inhibition of vascular calcification & 61 \\
\hline $\begin{array}{l}\text { Human adipocytes subjected to } \\
\text { differentiation }\end{array}$ & Obesity & Olaparib $(1 \mu \mathrm{M})$ & $\begin{array}{l}\text { Reduced fat uptake and increased mitochondrial } \\
\text { biogenesis }\end{array}$ & 248 \\
\hline \multicolumn{5}{|l|}{ In vivo } \\
\hline Wild-type Caenorhabditis elegans & Ageing & Olaparib $(1 \mu \mathrm{M})$ & $\begin{array}{l}\text { Maintenance of cellular bioenergetics and } \\
\text { extension of lifespan }\end{array}$ & 231 \\
\hline C. elegans with ATM mutation & Ataxia telangiectasia & Olaparib (500 nM) & Improvement of movement and memory & 235 \\
\hline $\begin{array}{l}\text { Drosophila prepupae subjected to } \\
\text { tachypacing }\end{array}$ & Atrial fibrillation & $\begin{array}{l}\text { Olaparib or veliparib } \\
(200-400 \mu \mathrm{M})\end{array}$ & $\begin{array}{l}\text { Protection against } \mathrm{NAD}^{+} \text {depletion and } \\
\text { improved cardiac contractility }\end{array}$ & 247 \\
\hline $\begin{array}{l}\text { Mice subjected to toxic doses of } \\
\text { doxorubicin }\end{array}$ & $\begin{array}{l}\text { Side effects of } \\
\text { chemotherapy }\end{array}$ & Rucaparib $\left(10 \mathrm{mg} \mathrm{kg}^{-1}\right)$ & $\begin{array}{l}\text { Prevention of body weight loss and improvement } \\
\text { of renal function }\end{array}$ & 112 \\
\hline $\mathrm{db} / \mathrm{db}$ mice & Type 2 diabetes & $\begin{array}{l}\text { Veliparib }\left(15 \mathrm{mg} \mathrm{kg}^{-1}\right. \\
\text { daily) }\end{array}$ & Improved vascular function ex vivo & 229 \\
\hline $\begin{array}{l}\text { Dopaminergic neuron loss in AIMP2 } \\
\text { transgenic mice }\end{array}$ & Parkinson disease & $\begin{array}{l}\text { Rucaparib } \\
\left(0.125-1.25 \mathrm{mg} \mathrm{kg}^{-1}\right)\end{array}$ & $\begin{array}{l}\text { Prevention of degeneration of dopaminergic } \\
\text { neurons }\end{array}$ & 249 \\
\hline
\end{tabular}


Table 4 (cont.) | Clinically approved PARP inhibitors in models of non-oncological diseases

\begin{tabular}{|c|c|c|c|c|}
\hline Experimental model & Disease modelled & $\begin{array}{l}\text { Drug (concentration } \\
\text { or dose/dosage) }\end{array}$ & Effects & Refs \\
\hline \multicolumn{5}{|l|}{ In vivo (cont.) } \\
\hline Mice subjected to MCA occlusion & Acute ischaemic stroke & Olaparib (3-5 mg kg-1) & $\begin{array}{l}\text { Reduced infarct size and improved vascular and } \\
\text { neurological function }\end{array}$ & 250 \\
\hline $\begin{array}{l}\text { Mice administered with endotoxin } \\
\text { intratracheally }\end{array}$ & $\begin{array}{l}\text { ARDS, sepsis, acute } \\
\text { kidney injury }\end{array}$ & Olaparib $\left(5 \mathrm{mg} \mathrm{kg}^{-1}\right)$ & $\begin{array}{l}\text { Attenuation of inflammatory cell infiltration, } \\
\text { reduced cytokine production and improved } \\
\text { organ function }\end{array}$ & 251 \\
\hline Endotoxin-injected mice & Sepsis, liver failure & Olaparib $\left(50 \mathrm{mg} \mathrm{kg}^{-1}\right)$ & $\begin{array}{l}\text { Improved liver function and reduced } \\
\text { inflammatory gene expression }\end{array}$ & 240 \\
\hline $\begin{array}{l}\text { Mouse model of ovalbumin-induced or } \\
\text { dust mite-induced lung inflammation }\end{array}$ & Bronchial asthma & $\begin{array}{l}\text { Olaparib } \\
\left(1-10 \mathrm{mgkg}^{-1}\right)\end{array}$ & $\begin{array}{l}\text { Reduced lgE production, suppression of } \\
\text { inflammatory cell mobilization and inhibition } \\
\text { of cytokine production }\end{array}$ & 232,252 \\
\hline $\begin{array}{l}\text { Mouse fed with high-fat/high-sucrose } \\
\text { or methionine/choline-deficient diet }\end{array}$ & Fatty liver disease & $\begin{array}{l}\text { Olaparib } \\
\left(40-50 \mathrm{mg} \mathrm{kg}^{-1} \text { daily) }\right.\end{array}$ & $\begin{array}{l}\text { Reduced obesity, reduced hepatic fat } \\
\text { deposition, improved glucose tolerance and } \\
\text { improved metabolic function }\end{array}$ & 240,253 \\
\hline $\begin{array}{l}\text { Mice subjected to binge alcohol } \\
\text { exposure }\end{array}$ & Alcoholic hepatitis & $\begin{array}{l}\text { Olaparib }\left(50 \mathrm{mg} \mathrm{kg}^{-1}\right. \\
\text { daily) }\end{array}$ & $\begin{array}{l}\text { Improved hepatic function and reduced liver } \\
\text { inflammation }\end{array}$ & 253 \\
\hline rd1 or rd10 mice & Retinitis pigmentosa & $\begin{array}{l}\text { Olaparib }(0.1 \mu \mathrm{M} \\
\text { intravitreally })\end{array}$ & $\begin{array}{l}\text { Rescue of photoreceptors and protection } \\
\text { against cell death }\end{array}$ & 236,237 \\
\hline $\begin{array}{l}\text { Heterotopic heart transplantation in } \\
\text { Lewis rats }\end{array}$ & Transplant rejection & $\begin{array}{l}\text { Olaparib }\left(10 \mathrm{mg} \mathrm{kg}^{-1}\right. \\
\text { daily) }\end{array}$ & $\begin{array}{l}\text { Improved cardiac function and beneficial } \\
\text { regulation of gene expression in the } \\
\text { transplanted heart }\end{array}$ & 241 \\
\hline $\begin{array}{l}\text { Intrastriatal injection of } \alpha \text {-synuclein } \\
\text { in mice }\end{array}$ & Neurodegeneration & Veliparib $\left(125 \mathrm{mg} \mathrm{kg}^{-1}\right)$ & Protection against dopaminergic neuron loss & 59 \\
\hline Mice subjected to burn injury & Third-degree burns & $\begin{array}{l}\text { Olaparib }\left(10 \mathrm{mg} \mathrm{kg}^{-1}\right. \\
\text { daily) }\end{array}$ & $\begin{array}{l}\text { Improved organ function, attenuated } \\
\text { inflammatory mediator production and } \\
\text { accelerated wound healing }\end{array}$ & 254 \\
\hline $\begin{array}{l}\text { Mice subjected to caecal ligation and } \\
\text { puncture }\end{array}$ & Septic shock & $\begin{array}{l}\text { Olaparib } \\
\left(9-30 \mathrm{mg} \mathrm{kg}^{-1} \text { daily }\right)\end{array}$ & $\begin{array}{l}\text { Improved organ function, reduced } \\
\text { proinflammatory mediator production and } \\
\text { increased survival }\end{array}$ & 245 \\
\hline Cerulein-injected mice & Acute pancreatitis & $\begin{array}{l}\text { Olaparib } \\
\left(9-30 \mathrm{mg} \mathrm{kg}^{-1} \text { daily }\right)\end{array}$ & $\begin{array}{l}\text { Improved organ function and reduced } \\
\text { proinflammatory mediator production }\end{array}$ & 246 \\
\hline
\end{tabular}

ALS, amyotrophic lateral sclerosis; ARDS, acute respiratory distress syndrome; ATM, ataxia telangiectasia mutated; HMGB1, high mobility group protein B1; HPDE, human pancreatic duct epithelial; hVSMC, human vascular smooth muscle cell; MCA, middle cerebral artery; NMDA, N-methyl-D-aspartate; PARP, poly(ADP-ribose) polymerase; TDP43, TAR DNA-binding protein 43.

It will be difficult to define the selectivity of the PARP inhibitors until there is a consensus using several different methods. The ultimate confirmation of specificity is the lack of a biological effect in a cell lacking the proposed target. Two recent developments may aid the generation of more selective drugs. First, a novel immunological method for detecting MARylation and PARylation in vitro has recently been described, in which a panel of cell lines were genetically engineered to overexpress PARP family members and used to determine the activity of PARP inhibitors against specific PARPs. This approach has been used to identify inhibitors specific for PARP7 (REF. ${ }^{272}$ ). Second, non-NAD ${ }^{+}$-based PARP inhibitors could allow greater specificity through allosteric inhibition ${ }^{101}$.

It is probably advantageous to inhibit both PARP1 and PARP2 when treating cancer owing to their overlapping functions in DNA repair; however, PARP2selective inhibitors could offer advantages over existing PARP inhibitors. PARP2-deficient mice are highly sensitive to ionizing radiation, which induces chromosomal damage and lethality ${ }^{268}$. PARP2 has been implicated in DNA repair and in the maintenance of genomic integrity, in proliferative signalling through transforming growth factor- $\beta$ and in angiogenesis and the evasion of tumour cells from the host immune response ${ }^{269}$. These roles suggest that a PARP2 inhibitor might have anticancer potential. At the same time, PARP2 has also been implicated in the promotion of various inflammatory responses, including the facilitation of intestinal injury in colitis models ${ }^{270}$ and improved outcomes in neuroinflammation models ${ }^{271}$ in mice. These data must be interpreted with caution, because they are all based on studies using PARP2-deficient models, in which both the catalytic and the scaffolding activities of PARP2 are absent. This represents a different scenario to a cell treated with a PARP2 inhibitor, where only the catalytic aspects of the enzyme are inhibited. Nevertheless, the findings with PARP2-deficient models indicate that a selective PARP2 inhibitor may have anti-inflammatory potential. Inhibiting PARP2 specifically might also be safer and more suitable for chronic therapeutic regimens than simultaneous inhibition of PARP $1 / 2$ as it would be expected to have less of an inhibitory effect on DNA repair.

The other PARP family members capable of PARylation are the tankyrases PARP5A and PARP5B, which have roles in telomere maintenance, spindle 
assembly and WNT signalling (reviewed in REF. ${ }^{273}$ ). PARP5A and PARP5B PARylate telomeric repeatbinding factor 1 (TERF1) - a DNA-binding component of the shelterin protein complex that protects telomeres from DNA repair mechanisms - and inhibit its capacity to bind to $\mathrm{DNA}^{274}$. Limiting tumour immortality by specifically inhibiting tankyrases such as PARP5A and PARP5B is a potentially attractive proposition, particularly since the telomerase inhibitor imetelstat was given a fast-track designation for treatment of relapsed or refractory myelofibrosis by the FDA in late 2019. Even in cases where telomeres are elongated by the alternative lengthening of telomeres mechanism - a repair-based pathway used by cancer cells to maintain telomere length - the role of PARP5A in mitotic spindles is still a potential target to arrest tumour growth. The first reported 'selective' tankyrase inhibitors were XAV939 and IWR-1; other compounds identified include WIKI4, JW55, JW74, G007-LK, K-756 and AZ1366 (reviewed in REFS ${ }^{275-278}$ ). However, cell-based and in vivo studies with these inhibitors suggest more complex interactions than just tankyrase inhibition and less specificity for tankyrases over PARP1 or PARP2 than first thought, and hence interpretation of the data is difficult. At least one tankyrase inhibitor (E7449 from Oncology Venture) has entered the clinical trial stage ${ }^{279}$, with two phase II trials currently in the recruitment stage: one in advanced ovarian cancer (NCT03878849) and one in metastatic breast cancer (NCT03562832). Earlier studies demonstrated that E7449 has comparable inhibitory potency among PARP1, PARP2 and the tankyrases ${ }^{93}$; therefore, the relative contribution of tankyrase inhibition and the clinical validation of the tankyrases PARP5A and PARP5B as stand-alone oncological targets remain to be defined in future studies using more selective tankyrase inhibitors.

PARP3 plays a role in mediating DNA DSB repair, chromosomal rearrangements, mitotic segregation, mechanistic target of rapamycin complex 2 signalling, transforming growth factor- $\beta$-induced epithelialmesenchymal transition in breast cancer and the maintenance of stem cell traits, making it a prime target for cancer therapy ${ }^{280,281}$. Although PARP3 was initially thought to have poly(ADP-ribosyl)ation activity, it is now thought to be a mono(ADP-ribosyl)transferase. An inhibitor specific for PARP3 known as ME0328 is in early-stage development ${ }^{282}$; this compound has been shown to enhance the mitotic arrest induced by the chemotherapy agent vinorelbine, increasing vinorelbine cytotoxicity 10 -fold ${ }^{283}$. However, the potential of PARP3 inhibitors as possible future anticancer agents remains to be further elucidated.

Few formal development candidates have emerged that target MAR-producing members of the PARP superfamily. Aside from PARP3, the only notable exception is PARP7, also known as TIPARP - an enzyme implicated in the cellular stress responses and cancer. A small-molecule inhibitor of this enzyme, RBN-237, is in early-stage clinical trials (NCT04053673, Ribbon Therapeutics) in patients with advanced solid tumours; however, no information on RBN-237 has been publicly disclosed thus far.

\section{Outlook}

The fundamental biological roles of PARP1 continue to be revealed, with a recent study describing a role for PARP1 in the mitochondria ${ }^{284}$. Improvements in medicinal chemistry may yield further increases in the potency and selectivity of future generations of PARP inhibitors; for example, mitochondrially targeted PARP inhibitors ${ }^{243}$ may yield novel experimental therapeutic approaches and strategies in response to the findings described herein. Further, advances in our understanding of the pathogenesis of various diseases will undoubtedly identify pathways that interact with PARP1, and these advances may yield novel additive or synergistic therapeutic approaches that could be exploited by therapies that simultaneously target PARP1 and the relevant interacting pathway. Indeed, a class of bifunctional PARP inhibitors that also release nitric oxide have been synthesized, with the intention of targeting glutathione $S$-transferase $\mathrm{P} 1$-overexpressing cancer cells ${ }^{285}$. PARP1 and the AKT pathway overlap, and simultaneous modulation of these two systems may have applications in both oncological and non-oncological indications ${ }^{286}$.

The investigation of novel PARP targets will also lead to novel drug targets. Recent studies revealed that serine is a target for ADP-ribosylation in response to DNA damage, and ADP-ribosylation is dependent on histone PARylation factor 1 (HPF1) $)^{287,288}$. Subsequent studies showed that PARP1 competes with histone acetyltransferases for modification of adjacent serine and lysine residues on histones ${ }^{289}$, which has implications for the regulation of gene expression by PARP1 (reviewed in REF ${ }^{68}$ ). These findings will have implications for basic biology and the role of inhibitors in oncology and non-oncological areas. A large body of foundational work has also been performed in the area of PAR binding by macrodomains and tryptophan- and glutamate-rich (WWE) domains, as some of the proteins containing these domains are considered druggable oncology targets; the scientific background and the translational potential of this field have been discussed in recent comprehensive reviews ${ }^{290-293}$.

With respect to research and development related to members of the PARP superfamily other than PARP1, basic research unveiling the functional role of these proteins is expected to go hand-in-hand with medicinal chemistry advances producing inhibitors with increased selectivity and potency. These efforts may eventually yield novel first-in-class drug development candidates for oncological and non-oncological indications.

PARP1/2 inhibitors look to become a mainstay as single agents for treating certain classes of cancer. These inhibitors have proved highly effective in platinum-sensitive/homologous recombinationdeficient ovarian cancer, although perhaps less so in other tumours associated with BRCA mutations and an HRD phenotype such as breast, prostate and pancreatic cancers. Nevertheless, given the mild toxic effects of PARP $1 / 2$ inhibitors, these cancers are a worthwhile avenue to pursue. It is clear that $B R C A$ mutations cannot predict PARP inhibitor sensitivity in a tumour-agnostic fashion - there is a spectrum 
of PARP inhibitor sensitivity across $B R C A$-mutated cancers, with greater sensitivity in $B R C A$-mutant ovarian cancers than $B R C A$-mutant breast, prostate or pancreatic cancers, and $B R C A$-mutated cancers of types not normally associated with $B R C A$ carriers are even less sensitive to PARP inhibitor effects ${ }^{294,295}$. Although platinum sensitivity may be a useful surrogate for PARP inhibitor sensitivity in ovarian cancers, it is not in other cancers. Genomic screens such as the Myriad myChoice assay may help identify homologous recombination-deficient tumours; however, as they also detect genomic changes caused by the inability to perform HRR that persist even when HRR is restored (genomic scarring), they may give false positives by failing to identify tumours that have reversed the HRD phenotype and are therefore resistant to PARP inhibitors. The most reliable predictive biomarkers of HRD are likely to be functional, such as the ability of tumour cells to form RAD51 foci, which has been used to identify that around a third of abdominal tumours and a high frequency of lung tumours are homologous recombination deficient ${ }^{296,297}$.

The approved single-agent doses of olaparib, rucaparib, niraparib and talazoparib result from early trials that established the maximum tolerated dose, but it is unclear whether the maximum tolerated dose is appropriate for a tumour-selective drug that is not anticipated to damage normal tissue. It would therefore be better to use the optimum biological dose rather than maximum tolerated dose for improved quality of life. Further studies are needed to determine whether less-intense dose schedules that are likely to be less toxic and more affordable will be as effective as approved single-agent dose schedules.
Combinations of PARP inhibitors with genotoxic chemotherapy and radiotherapy remain limited by toxicity issues and the need for careful titration of the cytotoxic agent and the PARP inhibitor. Carefully designed dose schedules will be necessary to optimize the therapeutic index and may have to be considered on an individual basis. It is clear from preclinical and clinical data that compared with their use as single agents, shorter schedules and lower doses of PARP inhibitors are needed for efficacy and tolerability when used in combination with cytotoxic agents. Although the preclinical data in non-HRD cancers look promising for the combination of PARP inhibitors with DNA damage cell cycle checkpoint kinases, this combination may also result in increased toxicity such that there is no improvement in the therapeutic index. Time will tell whether these combinations will live up to their promise clinically. Non-HRD tumours are prime candidates for treatment with PARP inhibitors and immune checkpoint inhibitors, but again it remains to be seen whether this will be a gentler form of therapy compared with conventional cytotoxic agents combined with immuno-oncology agents.

Finally, there have been repeated calls in the literature for trials repurposing PARP inhibitors for the treatment of non-oncological indications such as critical illness, acute lung injury, lung fibrosis and acute and chronic neurological diseases ${ }^{205,227,228,245,246,298-302}$. To our knowledge, no such trials are ongoing; however, the success of ongoing clinical trials in stroke could reinvigorate pharmaceutical interest in these areas, especially since some of the potential target indications represent significant unmet needs and enormous commercial opportunities.
1. Gibson, B. A. \& Kraus, W. L. New insights into the molecular and cellular functions of poly(ADP-ribose) and PARPs. Nat. Rev. Mol. Cell Biol. 13, 411-424 (2012).

Kraus, W. L. PARPs and ADP-ribosylation: 50 years and counting. Mol. Cell 58, 902-910 (2015). Cohen, M. S. \& Chang, P. Insights into the biogenesis, function, and regulation of ADP-ribosylation. Nat. Chem. Biol. 14, 236-243 (2018).

4. Schuhwerk, H., Atteya, R., Siniuk, K. \& Wang, Z. Q. PARPing for balance in the homeostasis of poly(ADP-ribosyl)ation. Semin. Cell Dev. Biol. 63 81-91 (2017)

5. Palazzo, L. \& Ahel, I. PARPs in genome stability and signal transduction: implications for cancer therapy. Biochem. Soc. Trans. 46, 1681-1695 (2018).

6. Chambon, P., Weill, J. D., Doly, J., Strosser, M. T $\Sigma$ Mandel, P. On the formation of a novel adenylic compound by enzymatic extracts of liver nuclei. Biochem. Biophys. Res. Commun. 25, 638-643 (1966).

This study is the first to describe the formation of PAR.

7. Nishizuka, Y., Ueda, K., Nakazawa, K. \& Hayaishi, O. Studies on the polymer of adenosine diphosphate ribose. I. Enzymic formation from nicotinamide adenine dinuclotide in mammalian nuclei. J. Biol. Chem. 242, 3164-3171 (1967). Chem. 242, 3164-3171 (1967).
This study is the first to identify the enzyme This study

8. Ueda, K., Reeder, R. H., Honjo, T., Nishizuka, Y. \& Hayaishi, O. Poly adenosine diphosphate ribose synthesis associated with chromatin. Biochem. Biophys. Res. Commun 31, 379-385 (1968)

9. Otake, H., Miwa, M., Fujimura, S. \& Sugimura, T. Binding of ADP-ribose polymer with histone. J. Biochem. 65, 145-146 (1969).

10. Yamada, M., Miwa, M. \& Sugimura, T. Studies on poly (adenosine diphosphate-ribose): X. properties of partially purified poly (adenosine diphosphate-ribose) polymerase Arch Biochem. Biophys. 146, 579-586 (1971)

11. Juarez-Salinas, H., Sims, J. L. \& Jacobson, M. K Poly(ADP-ribose) levels in carcinogen-treated cells. Nature 282, 740-741 (1979).

This study documents an increase in PAR formation following DNA damage.

12. Benjamin, R. C. \& Gill, D. M. ADP-ribosylation in mammalian cell ghosts. Dependence of poly(ADPmammalian cell ghosts. Dependence of poly(ADP-
ribose) synthesis on strand breakage in DNA. J. Biol. Chem. 255, 10493-10501 (1980).

13. Purnell, M. R. $\&$ Whish, W. J. Novel inhibitors of poly(ADP-ribose) synthetase. Biochem. J. 185, 775-777 (1980). This study describes the synthesis of the first PARP inhibitor, 3-AB.

14. Poirier, G. G., de Murcia, G., Jongstra-Bilen, J., Niedergang, C. \& Mandel, P. Poly(ADP-ribosyl)ation of polynucleosomes causes relaxation of chromatin structure. Proc. Natl Acad. Sci. USA 79, 3423-3427 (1982)

15. Durkacz, B. W., Omidiji, O., Gray, D. A. \& Shall, S. (ADP-ribose) participates in DNA excision repair. Nature 283, 593-596 (1980).

This study is the first demonstration of the inhibition of DNA repair and increased cytotoxicity of a DNA-methylating agent by a PARP inhibitor.

16. Sims, J. L., Berger, S. J. \& Berger, N. A. Poly(ADPribose) polymerase inhibitors preserve nicotinamide adenine dinucleotide and adenosine $5^{\prime}$-triphosphate pools in DNA damaged cells: mechanism of stimulation of unscheduled DNA synthesis. Biochemistry 22, 5188-5194 (1983). Biochemistry 22, 5188-5194 (1983).
This study marks the formulation of the 'Berger hypothesis', describing how the activation of PARP can lead to depletion of cellular NAD ${ }^{+}$and ATP levels.
17. Schraufstatter, I. U., Hinshaw, D. B., Hyslop, P. A., Spragg, R. G. \& Cochrane, C. G. Oxidant injury of cells. DNA strand-breaks activate polyadenosine diphosphate-ribose polymerase and lead to depletion of nicotinamide adenine dinucleotide. J. Clin. Invest. 77, 1312-1320 (1986).

18. Suto, M. J., Turner, W. R., Arundel-Suto, C. M., Werbel, L. M. \& Sebolt-Leopold, J. S. Dihydroisoquinolinones: the design and synthesis of a new series of potent inhibitors of poly(ADP- ribose) polymerase. Anticancer Drug Des. 6, 107-117 (1991).

19. Arundel-Suto, C. M., Scavone, S. V., Turner, W. R., Suto, M. J. \& Sebolt-Leopold, J. S. Effect of PD 128763 , a new potent inhibitor of poly(ADP-ribose) polymerase, on X-ray-induced cellular recovery processes in Chinese hamster V79 cells. Rad. Res. 126, 367-371 (1991)

20. Banasik, M. Komura, H., Shimoyama, M. \& Ueda, K. Specific inhibitors of poly(ADP-ribose) synthetase and mono(ADP-ribosyl)transferase. J. Biol. Chem. 267, 1569-1575 (1992)

This study identifies several commercially available compounds that inhibit PARP. These molecules served as templates for further PARP inhibitor design and development efforts.

21. Satoh, M. S. \& Lindahl, T. Role of poly(ADP-ribose) formation in DNA repair. Nature 356, 356-358 (1992).

This is the first demonstration of PARP 'trapping'

22. Zhang, J., Dawson, V. L., Dawson, T. M. \& Snyder, S. H. Nitric oxide activation of poly (ADP-ribose) synthetase in neurotoxicity. Science 263, 687-689 (1994)

23. Heller, B. et al. Inactivation of the poly(ADP-ribose) polymerase gene affects oxygen radical and nitric oxide toxicity in islet cells. J. Biol. Chem. 270, 11176-11180 (1995)

24. Wang, Z. O. et al. Mice lacking ADPRT and poly(ADP-ribosyl)ation develop normally but are 
susceptible to skin disease. Genes Dev. 9, 509-520 (1995).

This study describes the generation of the Parp1knockout mouse

25. Szabo, C., Zingarelli, B., O'Connor, M. \& Salzman, A. L. DNA strand breakage, activation of poly (ADP-ribose) synthetase, and cellular energy depletion are involved in the cytotoxicity of macrophages and smooth muscle cells exposed to peroxynitrite. Proc. Natl Acad. Sci. USA 93, 1753-1758 (1996).

This study describes how PARP activation occurs in response to nitrosative stress and also describe the protective effect of PARP inhibition against cell death.

26. Ruf, A., Mennissier de Murcia, J., de Murcia, G. $\delta$ Schulz, G. E. Structure of the catalytic fragment of poly(AD-ribose) polymerase from chicken. Proc. Natl Acad. Sci. USA 93, 7481-7485 (1996).

27. Szabo, C. et al. Inhibition of poly (ADP-ribose) synthetase attenuates neutrophil recruitment and exerts anti-inflammatory effects. J. Exp. Med. 186 1041-1049 (1997)

This study demonstrates that PARP inhibition can suppress inflammation

28. Wang, Z. Q. et al. PARP is important for genomic stability but dispensable in apoptosis. Genes Dev. 11, 2347-2358 (1997)

29. de Murcia, J. M. et al. Requirement of poly(ADPribose) polymerase in recovery from DNA damage in mice and in cells. Proc. Natl Acad. Sci. USA 94, 7303-7307 (1997).

30. Meisterernst, M Stelzer, G. \& Roeder, R. C Poly(ADP-ribose) polymerase enhances activator dependent transcription in vitro. Proc. Natl Acad. Sci. USA 94, 2261-2265 (1997). This study is the first to link PARP to gene transcription events.

31. Rawling, J. M. \& Alvarez-Gonzalez, R. TFIIF, a basal eukaryotic transcription factor, is a substrate for poly(ADP-ribosyl)ation. Biochem. J. 324, 249-253 (1997).

32. Eliasson, M. J. et al. Poly(ADP-ribose) polymerase gene disruption renders mice resistant to cerebral ischemia. Nat. Med. 3, 1089-1095 (1997).

33. Zingarelli, B., Cuzzocrea, S., Zsengeller, Z., Salzman, A. L. $\&$ Szabo, C. Protection against myocardial ischemia and reperfusion injury by 3-aminobenzamide, an inhibitor of poly (ADP-ribose) synthetase. Cardiovasc. Res. 36, 205-215 (1997)

34. Virag, L., Salzman, A. L. \& Szabo, C. Poly(ADP-ribose) synthetase activation mediates mitochondrial injury during oxidant-induced cell death. J. Immunol. 161, 3753-3759 (1998).

This study shows PARP overactivation promotes a regulated form of cell necrosis in oxidatively stressed cells.

35. Amé, J. C. et al. PARP-2, a novel mammalian DNA damage-dependent poly(ADP-ribose) polymerase J. Biol. Chem. 274, 17860-17868 (1999). This is the first study to identify PARP2, which then stimulated the search for other PARPs and led to the identification of the PARP superfamily.

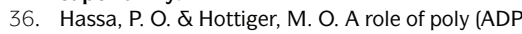 ribose) polymerase in NF-kB transcriptional activation Biol. Chem. 380, 953-959 (1999).

37. Oliver, F. J. et al. Resistance to endotoxic shock as a consequence of defective NF-kB activation in poly (ADP-ribose) polymerase-1 deficient mice. EMBO J. 18, 4446-4454 (1999)

38. Oei, S. L. \& Ziegler, M. ATP for the DNA ligation step in base excision repair is generated from poly(ADP-ribose). J. Biol. Chem. 275, 23234-23239 (2000).

39. Soriano, F. G. et al. Diabetic endothelial dysfunction the role of poly (ADP-ribose) polymerase activation. Nat. Med. 7, 108-113 (2001).

This study is the first to link PARP activation to diabetic complications.

40. Simbulan-Rosenthal, C. M. et al. Misregulation of gene expression in primary fibroblasts lacking poly(ADP-ribose) polymerase. Proc. Natl Acad. Sci. USA 97, 11274-11279 (2000)

41. Jagtap, P. et al. Novel phenanthridinone inhibitors of poly(adenosine 5'-diphosphate-ribose) synthetase: potent cytoprotective and antishock agents. Crit. Care Med. 30, 1071-1082 (2002)

42. Liaudet, L. et al. Activation of poly(ADP-ribose) polymerase is a central mechanism of lipopolysaccharide-induced acute pulmonary inflammation. Am. J. Resp. Crit. Care Med. 165, 372-377 (2002)
43. Yu, S. W. et al. Mediation of poly(ADP-ribose) polymerase-1- dependent cell death by apoptosis-inducing factor. Science 297, 259-263 (2002)

44. Veres, B. et al. The novel phenanthridinone inhibitor of poly(ADP-ribose) synthetase (PJ34) protects mice against LPS induced septic shock by decreasing inflammatory response and enhancing the cytoprotective Akt/protein kinase B pathway. Biochem. Pharmacol. 65, 1373-1382 (2003).

45. Menissier de Murcia, J. et al. Functional interaction between PARP-1 and PARP-2 in chromosome stability and embryonic development in mouse. $E M B O \mathrm{~J} . \mathbf{2 2}$, 2255-2263 (2003).

46. Schreiber, V., Dantzer, F., Ame, J. C. \& de Murcia, G. Poly(ADP-ribose): novel functions for an old molecule. Nat. Rev. Mol. Cell Biol. 7, 517-528 (2006)

47. Jagtap, P. G. et al. Discovery of potent poly(ADPribose) polymerase-1 inhibitors from the modification of indeno[1,2-c]isoquinolinone. J. Med. Chem. 48, 5100-5103 (2005)

48. Bryant, H. E. et al. Specific killing of BRCA2-deficient tumours with inhibitors of poly(ADP-ribose) polymerase. Nature 434, 913-917 (2005)

49. Farmer, H. et al. Targeting the DNA repair defect in BRCA mutant cells as a therapeutic strategy. Nature 434, 917-921 (2005).

The studies by Farmer et al. and Bryant et al. (2005) together are the first to identify the synthetic lethality of PARP inhibitors in BRCA-mutant cells and tumours.

50. Thomas, H. D. et al. Preclinical selection of a nove poly(ADP-ribose) polymerase inhibitor for clinical trial. Mol. Cancer Ther. 6, 945-956 (2007).

51. Menear, K. A. et al.

4-[3-(4-Cyclopropanecarbonylpiperazine-1-carbonyl)4-fluorobenzyl]-2H-phthalazin-1-one: a novel bioavailable inhibitor of poly(ADP-ribose) polymerase-1. J. Med. Chem. 51, 6581-6591 polyme
(2008).

52. Andrabi, S. A. et al. Poly(ADP-ribose) (PAR) polymer is a death signal. Proc. Natl Acad. Sci. USA 103, 18308-18313 (2006)

This study is the first to recognize PAR as an independent mediator of cell death

53. Bai, P. et al. PARP-1 inhibition increases mitochondrial metabolism through SIRT1 activation. Cell Metab. 13, 461-468 (2011).

54. Langelier, M. F., Planck, J. L., Roy, S. \& Pascal, J. M. Structural basis for DNA damage-dependent poly(ADP-ribosyl)ation by human PARP-1. Science 336, 728-732 (2012)

55. Kang H. C. et al. Iduna is a poly(ADP-ribose) (PAR)-dependent E3 ubiquitin ligase that regulates DNA damage. Proc. Natl Acad. Sci. USA 108, 14103-14108 (2011).

56. DaRosa, P. A. et al. Allosteric activation of the RNF146 ubiquitin ligase by a poly(ADP-ribosyl)ation signal. Nature 517, 223-226 (2015).

57. Andrabi, S. A. et al. Poly(ADP-ribose) polymerasedependent energy depletion occurs through inhibition of glycolysis. Proc. Natl Acad. Sci. USA 111 10209-10214 (2014).

58. Wright, R. H. et al. ADP-ribose-derived nuclear ATP synthesis by NUDIX 5 is required for chromatin remodeling. Science 352, 1221-1225 (2016).

59. Kam, T. I. et al. Poly(ADP-ribose) drives pathologic $\alpha$-synuclein neurodegeneration in Parkinson's disease. Science 362, eaat8407 (2018) This study describes PAR-related protein modification as a contributor to neurodegeneration.

60. Zimmermann, M. et al. CRISPR screens identify genomic ribonucleotides as a source of PARP-trapping lesions. Nature 559, 285-289 (2018).

61. Müller, K. H. et al. Poly(ADP-ribose) links the DNA damage response and biomineralization. Cell Rep. 27 3124-3138 (2019).

62. Caron, M. C. et al. Poly(ADP-ribose) polymerase-1 antagonizes DNA resection at double-strand breaks. Nat. Commun. 10, 2954 (2019).

63. Ruiz, P. D. et al. MacroH2A1 regulation of poly(ADP ribose) synthesis and stability prevents necrosis and promotes DNA repair. Mol. Cell Biol. 40, e00230-19 (2019).

64. Masutani, M. et al. Poly(ADP-ribose) polymerase gene disruption conferred mice resistant to streptozotocininduced diabetes. Proc. Natl Acad. Sci. USA 96 2301-2304 (1999).

65. Pascal, J. M. \& Ellenberger, T. The rise and fall of poly(ADP-ribose): an enzymatic perspective. DNA Repair 32, 10-16 (2015)
66. Langelier, M. F., Eisemann, T., Riccio, A. A. \& Pascal, J. M. PARP family enzymes: regulation and catalysis of the poly(ADP-ribose) posttranslational modification Curr. Opin. Struct. Biol. 53, 187-198 (2018).

67. Kraus, W. L. \& Hottiger, M. O. PARP-1 and gene regulation: progress and puzzles. Mol. Asp. Med. 34 1109-1123 (2013).

68. Ryu, K. W., Kim, D. S. \& Kraus, W. L. New facets in the regulation of gene expression by ADP-ribosylation and poly(ADP-ribose) polymerases. Chem. Rev. 115, 2453-2481 (2015)

69. Wang, Y., Luo, W. \& Wang, Y. PARP-1 and its associated nucleases in DNA damage response. DNA Repair 81, 102651 (2019)

70. Eisemann, T. \& Pascal, J. M. Poly(ADP-ribose) polymerase enzymes and the maintenance of genome integrity. Cell. Mol. Life Sci. 21, 1-5 (2020).

71. Donà, F. et al. Poly(ADP-ribosylation) and neoplastic transformation: effect of PARP inhibitors. Curr. Pharm. Biotechnol. 14, 524-536 (2013).

72. Rodríguez, M. I. et al. Deciphering the insights of poly(ADP-ribosylation) in tumor progression. Med. Res. Rev. 35, 678-697 (2015).

73. Bai, P. \& Cantó, C. The role of PARP-1 and PARP-2 enzymes in metabolic regulation and disease. Cell Metab. 16, 290-295 (2012).

74. Vida, A., Márton, J., Mikó, E. \& Bai, P. Metabolic roles of poly(ADP-ribose) polymerases. Semin. Cell Dev. Biol. 63, 135-143 (2017).

75. Gupte, R., Liu, Z. \& Kraus, W. L. PARPs and ADPribosylation: recent advances linking molecular functions to biological outcomes. Genes Dev. 31, 101-126 (2017).

76. Kunze, F. A. \& Hottiger, M. O. Regulating immunity via ADP-ribosylation: therapeutic implications and beyond. Trends Immunol. 40, 159-173 (2019).

77. Virāg, L., Robaszkiewicz, A., Rodriguez-Vargas, J. M. \& Oliver, F. J. Poly(ADP-ribose) signaling in cell death. Mol. Asp. Med. 34, 1153-1167 (2013).

78. Bürkle, A. ¿ Virăg, L. Poly(ADP-ribose): PARadigms and PARadoxes. Mol. Asp. Med. 34, 1046-1065 (2013).

79. Jubin, T. et al. Poly ADP-ribose polymerase-1: beyond transcription and towards differentiation. Semin. Cell Dev. Biol. 63, 167-179 (2017).

80. Bürkle, A., Grube, K. \& Küpper, J. H. Poly(ADP-ribosyl) ation: its role in inducible DNA amplification, and its correlation with the longevity of mammalian species. Exp. Clin. Immunogenet. 9, 230-240 (1992).

81. Vida, A., Abdul-Rahman, O., Mikó, E., Brunyănszki, A. $\&$ Bai, P. Poly(ADP-ribose) polymerases in aging friend or foe? Curr. Protein Pept. Sci. 17, 705-712 (2016).

82. Szabō, C. Nicotinamide: a jack of all trades (but master of none?). Int. Care Med. 29, 863-866 (2003).

83. Burkart, V., Blaeser, K. \& Kolb, H. Potent beta-cell protection in vitro by an isoquinolinone-derived PARP inhibitor. Horm. Metab. Res. 31, 641-644 (1999).

84. Calabrese C. R. et al Identification of potent nontoxic poly(ADP-ribose) polymerase-1 inhibitors: chemopotentiation and pharmacological studies. Clin. Cancer Res. 9, 2711-2718 (2003)

85. Bowman, K. J., White, A., Golding, B. T., Griffin, R \& Curtin, N. J. Potentiation of anticancer agent cytotoxicity by the potent poly(ADP-ribose) polymerase inhibitors, NU1025 and NU1064. Br. J. Cancer 78, 1269-1277 (1998)

86. Bowman, K. J., Newell, D. R., Calvert, A. H. \& Curtin, N. J. Differential effects of the poly(ADP-ribose) polymerase (PARP) inhibitor NU1025 on topoisomerase I and II inhibitor cytotoxicity. Br. J. Cancer $\mathbf{8 4}$ 106-112 (2001).

This study is the first to describe inhibition of DNA repair and enhancement of the cytotoxicity of topoisomerase 1 poisons by PARP inhibition.

87. McDonald, M. C. et al. Effects of 5-aminoisoquinolinone, a water-soluble, potent inhibitor of the activity of poly (ADP-ribose) polymerase on the organ injury and dysfunction caused by haemorrhagic shock. Br. J. Pharmacol. $130,843-850(2000)$

88. Zhang, J. et al. GPI 6150 prevents $\mathrm{H}_{2} \mathrm{O}_{2}$ cytotoxicity by inhibiting poly(ADP-ribose) polymerase. Biochem. Biophys. Res. Commun. 278, 590-598 (2000).

89. Nicolescu, A. C., Holt, A., Kandasamy, A. D., Pacher, P $\&$ Schulz, R. Inhibition of matrix metalloproteinase-2 by PARP inhibitors. Biochem. Biophys. Res. Commun. 387, 646-650 (2009). 
90. Jones, P. et al. Discovery of 2-\{4-[(3S)-piperidin-3-yl] phenyl $\}$-2H-indazole-7-carboxamide (MK-4827) a novel oral poly(ADP-ribose)polymerase (PARP) inhibitor efficacious in BRCA-1 and -2 mutant tumors. J. Med. Chem. 52, 7170-7185 (2009).

91. Shen, Y. et al. BMN 673, a novel and highly potent PARP $1 / 2$ inhibitor for the treatment of human cancers with DNA repair deficiency. Clin. Cancer Res. 19 5003-5015 (2013)

92. Donawho, C. K. et al. ABT-888, an orally active poly(ADP-ribose) polymerase inhibitor that potentiates DNA-damaging agents in preclinical tumor models. Clin. Cancer Res. 13, 2728-2737 (2007).

93. McGonigle, S. et al. E7449: A dual inhibitor of PARP $1 / 2$ and tankyrase $1 / 2$ inhibits growth of DNA repair deficient tumors and antagonizes Wnt signaling. Oncotarget 6, 41307-41323 (2015)

94. Miknyoczki, S. et al. The selective poly(ADP-ribose) polymerase-1(2) inhibitor, CEP-8983, increases the sensitivity of chemoresistant tumor cells to temozolomide and irinotecan but does not potentiate myelotoxicity. Mol. Cancer Ther. 6, 2290-2302 (2007).

95. Tang, Z. et al. BGB-290: A highly potent and specific PARP1/2 inhibitor potentiates anti-tumor activity of chemotherapeutics in patient biopsy derived SCLC models. Cancer Res. 75, S1653 (2015)

96. Wang, L. et al. Pharmacologic characterization of fluzoparib, a novel poly(ADP-ribose) polymerase inhibitor undergoing clinical trials. Cancer Sci. 110 1064-1075 (2019)

97. Kim, Y. et al. Neuroprotective effects of a novel poly (ADP-ribose) polymerase-1 inhibitor, JPI-289, in hypoxic rat cortical neurons. Clin. Exp. Pharmacol. Physiol. 44, 671-679 (2017).

98. Cao, J. et al. Pooled analysis of phase I dose-escalation and dose cohort expansion studies of IMP4297, a novel PARP inhibitor, in Chinese and Australian patients with advanced solid tumors. J. Clin. Oncol. 37, 3059 (2019)

99. Ferraris, D. V. Evolution of poly(ADP-ribose) polymerase-1 (PARP-1) inhibitors. From concept to clinic. J. Med. Chem. 53, 4561-4584 (2010).

100. Lord, C. J. \& Ashworth, A. PARP inhibitors: synthetic lethality in the clinic. Science 355, 1152-1158 (2017).

101. Jain, P. G. \& Patel, B. D. Medicinal chemistry approaches of poly ADP-Ribose polymerase 1 (PARP1) inhibitors as anticancer agents - a recent update. Eur. J. Med. Chem. 165, 198-215 (2019).

102. Miller, E. G. Stimulation of nuclear poly (adenosine diphosphate-ribose) polymerase activity from HeLa cells by endonucleases. Biochim. Biophys. Acta 395 191-200 (1975).

103. Davies, M. I. Halldorsson, H., Nduka, N., Shall, S $£$ Skidmore, C. J. The involvement of poly(adenosine diphosphate-ribose) in deoxyribonucleic acid repair Biochem. Soc. Trans. 6, 1056-1057 (1978).

104. Skidmore, C. J. et al. The involvement of poly(ADPribose) polymerase in the degradation of NAD caused by gamma-radiation and $\mathrm{N}$-methyl- $\mathrm{N}$-nitrosourea. Eur. J. Biochem. 101, 135-142 (1979).

105. Ben-Hur, E., Chen, C.-C. \& Elkind, M. M. Inhibitors of poly(adenosine diphosphoribose)synthetase, examination of metabolic perturbations and enhancement of radiation response in Chinese hamster cells. Cancer Res. 45, 2123-2127 (1985). This is the first demonstration of radiosensitization by PARP inhibition.

106. Parsons, J. L. \& Dianov, G. L. Co-ordination of base excision repair and genome stability. DNA Repair 12, 326-333 (2013)

107. Krokan, H. E. \& Bjørås, M. Base excision repair. Cold Spring Harb. Perspect. Biol. 5, a012583 (2013).

108. Caldecott, K. W. Protein ADP-ribosylation and the cellular response to DNA strand breaks. DNA Repair $19,108-113$ (2014).

109. Martin-Hernandez, K., Rodriguez-Vargas, J. M., Schreiber, V. \& Dantzer, F. Expanding functions of ADP-ribosylation in the maintenance of genome integrity. Semin. Cell Dev. Biol. 63, 92-101 (2017)

110. Li, M. \& Yu, X. The role of poly(ADP-ribosyl)ation in DNA damage response and cancer therapy. Oncogene 34, 3349-3356 (2015).

111. Dulaney, C., Marcrom, S., Stanley, J. \& Yang, E. S. Poly(ADP-ribose) polymerase activity and inhibition in cancer. Semin. Cell Dev. Biol. 63, 144-153 (2017).

112. Pascal, J. M. The comings and goings of PARP- 1 in response to DNA damage. DNA Repair 71, 177-182 (2018).
113. Noël, G. et al. Poly(ADP-ribose) polymerase (PARP-1) is not involved in DNA double-strand break recovery. BMC Cell Biol. 4, 7 (2003)

114. Ali, M. et al. The clinically active PARP inhibitor AG014699 ameliorates cardiotoxicity but doesn't enhance the efficacy of doxorubicin despite improving tumour perfusion and radiation response. Mol. Cancer Ther. 10, 2320-2329 (2011).

115. Evers, B. et al. Selective inhibition of BRCA2-deficient mammary tumor cell growth by AZD2281 and cisplatin. Clin. Cancer Res. 14, 3916-3925 (2008).

16. Haince, J. F. et al. PARP1-dependent kinetics of recruitment of MRE 11 and NBS1 proteins to multiple DNA damage sites. J. Biol. Chem. 283, 1197-1208 (2008)

117. Hochegger, H. et al. Parp-1 protects homologous recombination from interference by $\mathrm{Ku}$ and Ligase IV in vertebrate cells. EMBO J. 25, 1305-1314 (2006)

118. Schultz, N., Lopez, E., Saleh-Gohari, N. \& Helleday, T Poly(ADP-ribose) polymerase (PARP-1) has a controlling role in homologous recombination. Nucleic Acids Res. 31, 4959-4964 (2003)

119. Hanzlikova, H. et al. The importance of poly(ADPribose) polymerase as a sensor of unligated Okazaki fragments during DNA replication. Mol. Cell 71 319-331.e3 (2018)

120. Kedar, P. S., Stefanick, D. F., Horton, J. K. \& Wilson, S. H. Increased PARP-1 association with DNA in alkylation damaged, PARP-inhibited mouse fibroblasts. Mol. Cancer Res. 10, 360-368 (2012).

121. Pommier, Y., O'Connor, M. J. \& de Bono, J. Laying a trap to kill cancer cells: PARP inhibitors and their mechanisms of action. Sci. Transl. Med. 8, 362ps 17 (2016)

122. Murai, J. et al. Stereospecific PARP trapping by BMN 673 and comparison with olaparib and rucaparib. Mol Cancer Ther 13, 433-443 (2014).

123. Zandarashvili, L. et al. Structural basis for allosteric PARP-1 retention on DNA breaks. Science. 368 eaax6367 (2020).

124. Min, A. \& Im, S. A. PARP inhibitors as therapeutics: beyond modulation of PARylation. Cancers 12, 394 (2020).

125. Petermann, E., Ziegler, M. \& Oei, S. L. ATP-dependent selection between single nucleotide and long patch base excision repair. DNA Repair 2, 1101-1114 (2003)

126. Lazebnik, Y. A., Kaufmann, S. H., Desnoyers, S Poirier, G. G. \& Earnshaw, W. C. Cleavage of poly(ADPribose) polymerase by a proteinase with properties like ICE. Nature 371, 346-347 (1994). This is the first demonstration of PARP cleavage and its link to apoptosis.

127. Nicholson, D. W. et al. Identification and inhibition of the ICE/CED-3 protease necessary for mammalian apoptosis. Nature 376, 37-43 (1995)

28. Curtin, N. J. PARP inhibitors for cancer therapy. Expert. Rev. Mol. Med. 7, 1-20 (2005)

129. Calabrese, C. R. et al. Preclinical evaluation of a nove poly(ADP-ribose) polymerase-1 (PARP-1) inhibitor, AG14361, with significant anticancer chemo- and radio-sensitization activity. J. Nat. Cancer Inst. 96, 56-67 (2004).

130. Plummer, R. et al. Phase I study of the poly(ADP ribose) polymerase inhibitor, AG014699, in combination with temozolomide in patients with advanced solid tumors. Clin. Cancer Res. 14 7917-7923 (2008).

This article describes the first clinical trial of a PARP inhibitor, in which rucaparib was evaluated in combination with temozolomide.

131. Lesueur, P. et al. Poly-(ADP-ribose)-polymerase inhibitors as radiosensitizers: a systematic review of pre-clinical and clinical human studies. Oncotarget 8 69105-69124 (2017)

132. Powell, C., Mikropoulos, C. \& Kaye, S. B. Pre-clinical and clinical evaluation of PARP inhibitors as tumourspecific radiosensitisers. Cancer Treat. Rev. 36 , 566-575 (2010).

133. Lu, Y., Liu, Y., Pang, Y., Pacak, K. \& Yang, C. Double barreled gun: combination of PARP inhibitor with conventional chemotherapy. Pharmacol. Ther. 188 168-175 (2018).

134. Sachdev, E., Tabatabai, R., Roy, V., Rimel, B. J. \& Mita, M. M. PARP inhibition in cancer: An update on clinical development. Target. Oncol. 14, 657-679 (2019)

135. Lindahl, T., Satoh, M. S., Poirier, G. G. \& Klungland, A Post-translational modification of poly(ADP-ribose) polymerase induced by DNA strand breaks. Trends Biochem. Sci. 20, 405-411 (1995).
36. Saleh-Gohari, N. et al. Spontaneous homologous ecombination is induced by collapsed replication forks that are caused by endogenous DNA singlestrand breaks. Mol. Cell. Biol. 25, 7158-7169 (2005).

137. Venkitaraman, A. R. Functions of BRCA 1 and BRCA2 in the biological response to DNA damage. J. Cell Sci. 114, 3591-3598 (2001)

138. Fong, P. C. et al. Inhibition of poly(ADP-ribose) polymerase in tumors from BRCA mutation carriers. N. Engl. J. Med. 361, 123-134 (2009). This article describes the first clinical trial of a PARP inhibitor as a single agent (olaparib).

139. De Lorenzo, S. B. Patel, A. G. Hurley, R. M \& Kaufmann, S. H. The elephant and the blind men: Making sense of PARP inhibitors in homologous recombination deficient tumor cells. Front. Oncol. 3 228 (2013).

140. Gelmon, K. A. et al. Olaparib in patients with recurrent high-grade serous or poorly differentiated ovarian carcinoma or triple-negative breast cancer: a phase 2, multicentre, open-label, non-randomised study. Lancet Oncol. 12, 852-861 (2011).

141. Mukhopadhyay, A. et al. Development of a functional assay for homologous recombination status in primary cultures of epithelial ovarian tumor and correlation with sensitivity to PARP inhibitors. Clin. Cancer Res. 16, 2344-2351 (2010)

This is the first demonstration that more than $50 \%$ of ovarian cancers are HRR defective.

142. Konstantinopoulos, P. A et al. Gene expression profile of BRCAness that correlates with responsiveness to chemotherapy and with outcome in patients with epithelial ovarian cancer. J. Clin. Oncol. 28, 3555-3561 (2010).

143. Jenner, Z. B., Sood, A. K. \& Coleman, R. L. Evaluation of rucaparib and companion diagnostics in the PARP inhibitor landscape for recurrent ovarian cancer therapy. Future Oncol. 12, 1439-1456 (2016).

144. Gulhan, D. C., Lee, J. J., Melloni, G. E. M. Cortés-Ciriano, I. \& Park, P. J. Detecting the mutational signature of homologous recombination deficiency in clinical samples. Nat. Genet. $\mathbf{5 1}$, 912-919 (2019).

145. Ledermann, J., Harter, P., Gourley, C. et al. Olaparib maintenance therapy in patients with platinumsensitive relapsed serous ovarian cancer: a preplanned retrospective analysis of outcomes by BRCA status in a randomised phase 2 trial. Lancet Oncol. 15, 852-861 (2019).

This article describes the clinical trial leading to first approval of olaparib.

146. Drew, Y. et al. Phase 2 multicentre trial investigating intermittent and continuous dosing schedules of the poly(ADP-ribose) polymerase inhibitor rucaparib in germline BRCA mutation carriers with advanced ovarian and breast cancer. Br. J. Cancer 114 723-730 (2016).

147. Kristeleit, R. et al. A phase I-II study of the oral PARP inhibitor rucaparib in patients with germline BRCA1/2-mutated ovarian carcinoma or other solid tumors. Clin. Cancer Res. 23, 4095-4106 (2017).

148. Swisher, E. M. et al. Rucaparib in relapsed, platinumsensitive high-grade ovarian carcinoma (ARIEL2 part 1) an international, multicentre, open-label, phase 2 trial. Lancet Oncol. 18, 75-87 (2017).

149. Oza, A. M. et al. Antitumor activity and safety of the PARP inhibitor rucaparib in patients with high-grade ovarian carcinoma and a germline or somatic BRCA 1 or BRCA2 mutation: Integrated analysis of data from Study 10 and ARIEL2. Gynecol. Oncol. 147, 267-275 (2017)

150. Coleman, R. L. et al. Rucaparib maintenance treatment for recurrent ovarian carcinoma after response to platinum therapy (ARIEL3): a randomised, double-blind, placebo-controlled, phase 3 trial. Lancet 390, 1949-1961 (2017).

The studies by Coleman et al., Drew et al. (2016), Kristeleit et al. (2017), Swischer et al. (2017) and Oza et al. (2017) together describe the clinical trials that contributed to the first approval of rucaparib

151. Mirza, M. R. et al. Niraparib maintenance therapy in platinum-sensitive, recurrent ovarian cancer. N. Engl. Med. 375, 2154-2164 (2016). This study describes the clinical trial leading to the first approval of niraparib.

152. Moore, K. N. et al. Niraparib monotherapy for late-line treatment of ovarian cancer (QUADRA): a multicentre, open-label, single-arm, phase 2 trial. Lancet Oncol. 20, 636-648 (2019). 
153. Litton, J. K. et al. Talazoparib in patients with advanced breast cancer and a germline BRCA mutation. N. Engl. J. Med. 379, 753-763 (2018). This study describes the clinical trial leading to first approval of talazoparib

154. LaFargue, C. J., Dal Molin, G. Z., Sood, A. K. \& Coleman, R. L. Exploring and comparing adverse events between PARP inhibitors. Lancet Oncol. 20 e15-e28 (2019)

55. Murthy, P. \& Muggia, F. PARP inhibitors: clinical development, emerging differences and the current therapeutic issues. Cancer Drug Resist. 2, 665-679 (2019).

156. Adashek, J. J., Jain, R. K. \& Zhang, J. Clinical development of PARP inhibitors in treating metastatic castrate-resistant prostate cancer. Cells 8 860 (2019).

57. Golan, T. et al. Maintenance olaparib for germline BRCA-mutated metastatic pancreatic cancer. N. Engl. J. Med. 381, 317-327 (2019).

58. Pujade-Lauraine, E. et al. Olaparib tablets as maintenance therapy in patients with platinumsensitive, relapsed ovarian cancer and a BRCA $1 / 2$ mutation (SOLO2/ENGOT-Ov21): a double-blind, randomised, placebo-controlled, phase 3 trial. Lancet Oncol. 18, 1274-1284 (2017).

159. Moore, K. et al. Maintenance olaparib in patients with newly diagnosed advanced ovarian cancer. $N$. Engl. J. Med. 379, 2495-2505 (2018)

160. Robson, M. et al. Olaparib for metastatic breast cancer in patients with a germline BRCA mutation. N. Engl. J. Med. 377, 523-533 (2017)

161. Ramalingam, S. S. et al. Randomized, placebocontrolled, phase II study of veliparib in combination with carboplatin and paclitaxel for advanced metastatic non-small cell lung cancer. Clin. Cancer Res. 23, 1937-1944 (2017).

162. Shen, Y., Aoyagi-Scharber, M. \& Wang, B. Trapping poly(ADP-ribose) polymerase. J. Pharmacol. Exp. Ther 353, 446-457 (2015)

163. Kleinberg, L. et al. Phase I adult brain tumour consortium (ABTC) trial of ABT-888 (veliparib), temozolomide (TMZ) and radiotherapy (RT) for newly diagnosed glioblastoma multiforme (GBM) including pharmacokinetic (PK) data. J. Clin. Oncol. 31 (Suppl.15), 2065 (2013)

164. Mehta M. P et al Veliparib in combination with whole brain radiation therapy in patients with brain metastases: results of a phase 1 study. J. Neurooncol. 122, 409-417 (2015)

165. Su, J. M. et al. A phase I trial of veliparib (ABT-888) and temozolomide in children with recurrent CNS tumors: a pediatric brain tumor consortium report. Neuro. Oncol. 16, 1661-1668 (2014).

166. Baxter, P. A. et al. A phase I//l clinical trial of veliparib (ABT-888) and radiation followed by maintenance therapy with veliparib and temozolomide in patients with newly diagnosed diffuse intrinsic pontine gliom (DIPG): a pediatric brain tumor consortium interim report of phase I study. J. Clin. Oncol. 33 (Suppl. 15), 10053 (2015)

167. Lickliter J. D et al. A phase I dose-escalation study of BGB-290, a novel PARP $1 / 2$ selective inhibitor in patients with advanced solid tumors. J. Clin. Oncol. 34 (Suppl. 15), e17049 (2016)

68. Friedlander, M. et al. Pamiparib in combination with tislelizumab in patients with advanced solid tumours: results from the dose-escalation stage of a multicentre open-label, phase $1 \mathrm{a} / \mathrm{b}$ trial. Lancet Oncol. 20 , 1306-1315 (2019).

169. Luo, J. et al. Fluzoparib increases radiation sensitivity of non-small cell lung cancer (NSCLC) cells without BRCA1/2 mutation, a novel PARP1 inhibitor undergoing clinical trials. J. Cancer Res. Clin. Oncol. $146,721-737$ (2020).

170. Xu, J. M. et al. Phase I study of fluzoparib, a PARP1 inhibitor in combination with apatinib and paclitaxe in patients (pts) with advanced gastric and gastroesophageal junction (GEJ) adenocarcinoma. J. Clin. Oncol. 37 (Suppl. 15), 4060 (2019).

171. Gupta, S. K. et al. PARP inhibitors for sensitization of alkylation chemotherapy in glioblastoma: impact of blood-brain barrier and molecular heterogeneity. Front. Oncol. 8, 670 (2019).

172. Kizilbash, S. H. et al. Restricted delivery of talazoparib across the blood-brain barrier limits the sensitizing effects of PARP inhibition on temozolomide therapy in glioblastoma. Mol. Cancer Ther. 16, 2735-2746 (2017).

73. Durmus, S. et al. Breast cancer resistance protein (BCRP/ABCG2) and P-glycoprotein (P-GP/ABCB1) restrict oral availability and brain accumulation of the
PARP inhibitor rucaparib (AG-014699). Pharm. Res. 32, 37-46 (2015)

174. Ding, L. et al. PARP inhibition elicits STINGdependent antitumor immunity in Brca1-deficient ovarian cancer. Cell Rep. 25, 2972-2980 e5 (2018)

175. Shen, J. et al. PARPi triggers the STING-dependent immune response and enhances the therapeutic efficacy of immune checkpoint blockade independent of BRCAness. Cancer Res. 79, 311-319 (2019). This study demonstrates the therapeutic potential of a PARP inhibitor in combination with immune checkpoint blockade.

176. Stewart, R. A. Pilie, P. G. \& Yap, T. A. Development of PARP and immune-checkpoint inhibitor combinations. Cancer Res. 78, 6717-6725 (2018).

177. Lee, E. K. \& Konstantinopoulos, P. A. Combined PARP and immune checkpoint inhibition in ovarian cancer. Trends Cancer 5, 524-528 (2019).

178. Wilson, R. H. et al. A phase I study of intravenous and oral rucaparib in combination with chemotherapy in patients with advanced solid tumours. Br. J. Cancer 116, 884-892 (2017).

179. Cree, I. A. \& Charlton, P. Molecular chess? Hallmarks of anti-cancer drug resistance. BMC Cancer 17, 10 (2017)

180. Sakai, W. et al. Functional restoration of BRCA2 protein by secondary BRCA2 mutations in BRCA2mutated ovarian carcinoma. Cancer Res. 69, 6381-6386 (2009).

This study identifies secondary mutations in $B R C A 2$ that restore BRCA2 function.

81. Norquist, B. et al. Secondary somatic mutations restoring BRCA $1 / 2$ predict chemotherapy resistance in hereditary ovarian carcinomas. J. Clin. Oncol. 29, 3008-3015 (2011).

182. Bunting, S. F. et al. 53BP1 inhibits homologous recombination in Brca1-deficient cells by blocking resection of DNA breaks. Cell 141, 243-254 (2010)

183. Hurley, R. M. et al. 53BP1 as a potential predictor of response in PARP inhibitor-treated homologous recombination-deficient ovarian cancer. Gynecol. Oncol. 153, 127-134 (2019).

84. Xu, G. et al. REV7 counteracts DNA double-strand break resection and affects PARP inhibition. Nature 521, 541-544 (2015).

185. Patel, A. G., Sarkaria, J. N. \& Kaufmann, S. H. Nonhomologous end joining drives poly(ADP-ribose) polymerase (PARP) inhibitor lethality in homologous recombination-deficient cells. Proc. Natl Acad. Sci. USA 108, 3406-3411 (2011).

186. Chaudhuri, R. A. et al. Replication fork stability confers chemoresistance in BRCA-deficient cells. Nature 535, 382-387 (2016)

187. Gogola, E. et al. Selective loss of PARG restores PARylation and counteracts PARP inhibitor-mediated synthetic lethality. Cancer Cell 33, 1078-1093 (2018)

188. Ibrahim, Y. H. et al. PI3K inhibition impairs BRCA1/2 expression and sensitizes BRCA-proficient triplenegative breast cancer to PARP inhibition. Cancer Discov. 2, 1036-1047 (2012).

189. Juvekar, A. et al. Combining a PI3K inhibitor with a PARP inhibitor provides an effective therapy for BRCA1-related breast cancer. Cancer Discov. 2, 1048-1063 (2012).

190. Mukhopadhyay, A., Drew, Y., Matheson, E. et al. Evaluating the potential of kinase inhibitors to suppress DNA repair and sensitise ovarian cancer cells to PARP inhibitors. Biochem. Pharmacol. 167 125-132 (2019).

191. Roos, W. P. \& Krumm, A. The multifaceted influence of histone deacetylases on DNA damage signalling and DNA repair. Nucleic Acids Res. 44, 10017-10030 (2016)

192. Peasland, A. et al. Identification and evaluation of potent novel ATR inhibitor, NU6027, in breast and ovarian cancer cell lines. Br. J. Cancer 105, 372-38 (2011)

This is the first article to show synergy between PARP inhibitors and ATR inhibitors.

93. Yazinski, S. A. et al. ATR inhibition disrupts rewired homologous recombination and fork protection pathways in PARP inhibitor-resistant BRCA-deficient cancer cells. Genes Dev. 31, 318-332 (2017)

194. Piliê, P. G., Gay, C. M., Byers, L. A., O'Connor, M. J. $\Sigma$ Yap, T. A. PARP inhibitors: extending benefit beyond BRCA-mutant cancers. Clin. Cancer Res. 25 3759-3771 (2019).

195. Haynes, B., Murai, J. \& Lee, J. M. Restored replication fork stabilization, a mechanism of PARP inhibitor resistance, can be overcome by cell cycle checkpoint inhibition. Cancer Treat. Rev. 71, 1-7 (2018).

196. Johnson, N. et al. Compromised CDK1 activity sensitizes BRCA-proficient cancers to PARP inhibition. Nat. Med. 17, 875-883 (2011).

197. Pacher, P. \& Szabo, C. Role of the peroxynitritepoly(ADP-ribose) polymerase pathway in human disease. Am. J. Pathol. 173, 2-13 (2008).

198. Curtin, N. J. \& Szabo, C. Therapeutic applications of PARP inhibitors: anticancer therapy and beyond. Mol. Asp. Med. 34, 1217-1256 (2013).

199. Szabó, C. \& Dawson, V. L. Role of poly(ADP-ribose) synthetase in inflammation and ischaemia-reperfusion. Trends Pharmacol. Sci. 19, 287-298 (1998).

200. Virág, L. ¿ Szabó, C. The therapeutic potential of poly(ADP-ribose) polymerase inhibitors. Pharmacol. Rev. 54, 375-429 (2002).

201. Jagtap, P. \& Szabō, C. Poly(ADP-ribose) polymerase and the therapeutic effects of its inhibitors. Nat. Rev. Drug Discov. 4, 421-440 (2005).

202. Giansanti, V., Donà, F., Tillhon, M. \& Scovassi, A. I. PARP inhibitors: new tools to protect from inflammation. Biochem. Pharmacol. 80, 1869-1877 (2010).

203. Bai, P. \& Virăg, L. Role of poly(ADP-ribose) polymerases in the regulation of inflammatory processes. FEBS Lett. 586, 3771-3777 (2012)

204. García, S. \& Conde, C. The role of poly(ADP-ribose) polymerase-1 in rheumatoid arthritis. Mediators Inflamm. 2015, 837250 (2015).

205. Henning, R. J., Bourgeois, M. \& Harbison, R. D. Poly(ADP-ribose) polymerase (PARP) and PARP inhibitors: mechanisms of action and role in cardiovascular disorders. Cardiovasc. Toxicol. 18 493-506 (2018).

206. Dawson, T. M. \& Dawson, V. L. Nitric oxide signaling in neurodegeneration and cell death. Adv. Pharmacol. 82, 57-83 (2018).

207. Halmosi, R. et al. PARP inhibition and postinfarction myocardial remodeling. Int. J. Cardiol. 217, S52-S59 (2016).

208. Tapodi, A. et al. PARP inhibition induces Akt-mediated cytoprotective effects through the formation of a mitochondria-targeted phospho-ATM-NEMO-AktmTOR signalosome. Biochem. Pharmacol. 162, 98-108 (2019)

209. Zingarelli, B Salzman, A. L. \& Szabo, C Genetic disruption of poly (ADP ribose) synthetase inhibits the expression of P-selectin and intercellular adhesion molecule-1 in myocardial ischemia-reperfusion injury. Circ. Res. 83, 85-94 (1998).

210. Liaudet, L. et al. Suppression of poly (ADP-ribose) polymerase activation by 3 -aminobenzamide in a rat model of myocardial infarction: long-term morphological and functional consequences. Br. J. Pharmacol. 133 . 1424-1430 (2001)

211. Tóth-Zsámboki, E. et al. Activation of poly(ADP-ribose) polymerase by myocardial ischemia and coronary reperfusion in human circulating leukocytes. Mol. Med 12, 221-228 (2006)

This study provides the first evidence in humans that PARP is activated in myocardial infarction

212. Khan, T. A. et al. Poly(ADP-ribose) polymerase inhibition improves postischemic myocardial function after cardioplegia-cardiopulmonary bypass. J. Am Coll. Surg. 197, 270-277 (2003)

213. Xiao, C. Y., Chen, M., Zsengellerr, Z. \& Szabo, C. Poly(ADP-ribose) polymerase contributes to the development of myocardial infarction in diabetic rats and regulates the nuclear translocation of apoptosisinducing factor. J. Pharmacol. Exp. Ther. 310 498-504 (2004)

214. Szabó, G. et al. Poly(ADP-ribose) polymerase nhibition attenuates biventricular reperfusion injury after orthotopic heart transplantation. Eur. J. Cardiothorac. Surg. 27, 226-234 (2005).

215. Roesner, J. P. et al. Therapeutic injection of PARP inhibitor INO-1001 preserves cardiac function in porcine myocardial ischemia and reperfusion without reducing infarct size. Shock 33, 507-512 (2010).

216. Szabo, C., Biser, A., Benko, R., Böttinger, E. ¿ Suszták, K. Poly(ADP-ribose) polymerase inhibitors ameliorate nephropathy of type 2 diabetic Lepr ${ }^{d b / a b}$ mice. Diabetes 55, 3004-3012 (2006).

217. Xiao, C. Y et al. Poly(ADP-ribose) polymerase promotes cardiac remodeling, contractile failure, and translocation of apoptosis-inducing factor in a murine experimental model of aortic banding and heart failure. J. Pharmacol. Exp. Ther. 312, 891-898 (2005). 
218. Clark, R. S. et al. Local administration of the poly(ADP ribose) polymerase inhibitor INO-1001 prevents NAD depletion and improves water maze performance after traumatic brain injury in mice. J. Neurotrauma $\mathbf{2 4}$ 1399-1405 (2007)

219. d'Avila, J. C. et al. Microglial activation induced by brain trauma is suppressed by post-injury treatment with a PARP inhibitor. J. Neuroinflammation 9, 31 (2012).

220. Cardinale, A., Paldino, E., Giampà, C., Bernardi, G. \& Fusco, F. R. PARP-1 inhibition is neuroprotective in the R6/2 mouse model of Huntington's disease. PLOS ONE 10, e0134482 (2015)

221. Morrow, D. A et al. A randomized, placebocontrolled trial to evaluate the tolerability, safety, pharmacokinetics, and pharmacodynamics of a potent inhibitor of poly(ADP-ribose) polymerase (INO-1001) in patients with ST-elevation myocardial infarction undergoing primary percutaneous coronary intervention: results of the TIMI 37 trial. J. Thromb. Thrombolysis 27, 359-364 (2009).

This study is the first clinical trial of a PARP inhibitor in a non-oncological indication (myocardial infarction).

222. Bedikian, A. Y. et al. A phase IB trial of intravenous INO-1001 plus oral temozolomide in subjects with unresectable stage-III or IV melanoma. Cancer Invest. 27, 756-763 (2009)

223. Kim, Y. et al. Early treatment with poly(ADP-ribose) polymerase-1 inhibitor (JPI-289) reduces infarct volume and improves long-term behavior in an animal model of ischemic stroke. Mol. Neurobiol. $\mathbf{5 5}$, 7153-7163 (2018)

224. Noh, M. Y. et al. Regulatory T cells increase after treatment with poly (ADP-ribose) polymerase-1 inhibitor in ischemic stroke patients. Int. Immunopharmacol. 60, 104-110 (2018).

225. Bracken, C et al. Inhibition of PARP1 attenuates rat renal ischemia reperfusion injury. J. Am. Soc. Nephrol. 29 (Suppl.), 882 Abstr. SA-PO561 (2018).

226. Feng, F. Y., de Bono, J. S., Rubin, M. A. \& Knudsen, K. E. Chromatin to clinic: the molecular rationale for PARP inhibitor function. Mol. Cell 58, 925-934 (2015).

227. Berger, N. A. et al. Opportunities for the repurposing of PARP inhibitors for the therapy of non-oncological diseases. Br. J. Pharmacol. 175, 192-222 (2018).

228. Olsen, A. L. \& Feany, M. B. PARP inhibitors and Parkinson's disease. N. Engl. J. Med. 380, 492-494 (2019)

229. Choi, S. K. et al. Poly(ADP-ribose) polymerase inhibition improves coronary arteriole function in type 2 diabetes mellitus. Hypertension 59, 1060-1068 (2012).

230. Mouchiroud, L. et al. The $\mathrm{NAD}^{+} /$sirtuin pathway modulates longevity through activation of mitochondrial UPR and FOXO signaling. Cell 154 430-441 (2013)

231. Pirinen, E. et al. Pharmacological inhibition of poly(ADP-ribose) polymerases improves fitness and mitochondrial function in skeletal muscle. Cell Metab. 19, 1034-1041 (2014)

232. Ghonim, M. A. et al. PARP inhibition by olaparib or gene knockout blocks asthma-like manifestation in mice by modulating $\mathrm{CD}^{+} \mathrm{T}$ cell function. J. Transl. Med. 13, 225 (2015)

233. Xu, J. C. et al. Cultured networks of excitatory projection neurons and inhibitory interneurons for studying human cortical neurotoxicity. Sci. Transl. Med. 8, 333ra48 (2016)

234. Rom, S. et al. PARP inhibition in leukocytes diminishes inflammation via effects on integrins/ cytoskeleton and protects the blood-brain barrier. J. Neuroinflammation 13, 254 (2016).

235. Fang, E. F. et al. NAD+ replenishment improves lifespan and healthspan in ataxia telangiectasia models via mitophagy and DNA repair. Cell Metab. 24, 566-581 (2016)

236. Sahaboglu, A. et al. Olaparib significantly delays photoreceptor loss in a model for hereditary retinal degeneration. Sci. Rep. 6, 39537 (2016).

237. Vidal-Gil, L., Sancho-Pelluz, J., Zrenner, E., Oltra, M. \& Sahaboglu, A. Poly ADP ribosylation and extracellular vesicle activity in rod photoreceptor degeneration. Sci. Rep. 9, 3758 (2019)

238. Jang, K. H. et al. AlF-independent parthanatos in the pathogenesis of dry age-related macular degeneration. Cell Death Dis. 8, e2526 (2017).

239. Trakkides, T. O. et al. Oxidative stress increases endogenous complement-dependent inflammatory and angiogenic responses in retinal pigment epithelial cells independently of exogenous complement sources. Antioxidants 8, 548 (2019).
240. Gariani, K. et al. Inhibiting poly ADP-ribosylation increases fatty acid oxidation and protects against fatty liver disease. J. Hepatol. 66, 132-141 (2017).

241. Korkmaz-Icöz, S. et al. Olaparib protects cardiomyocytes against oxidative stress and improves graft contractility during the early phase after heart transplantation in rats. Br. J. Pharmacol. 175 246-261 (2018).

242. McGurk, L. et al. Nuclear poly(ADP-ribose) activity is a therapeutic target in amyotrophic lateral sclerosis. Acta Neuropathol. Commun. 6, 84 (2018).

243. Krainz, T. et al. Synthesis and evaluation of a mitochondria-targeting poly(ADP-ribose) polymerase-1 inhibitor. ACS Chem. Biol. 13, 2868-2879 (2018)

244. Tajuddin, N., Kim, H. Y. \& Collins, M. A. PARP inhibition prevents ethanol-induced neuroinflammatory signaling and neurodegeneration in rat adult-age brain slice cultures. J. Pharmacol. Exp. Ther. 365, 117-126 (2018)

245. Ahmad, A. et al. The PARP inhibitor olaparib exerts beneficial effects in mice subjected to cecal ligature and puncture and in cells subjected to oxidative stress without impairing DNA integrity: A potential opportunity for repurposing a clinically used oncological drug for the experimental therapy of sepsis. Pharmacol. Res. 145, 104263 (2019).

246. Ahmad, A. et al. Effects of the poly(ADP-ribose) polymerase inhibitor olaparib in cerulein-induced pancreatitis. Shock 53, 653-665 (2020)

247. Zhang, D et al. DNA damage-induced PARP1 activation confers cardiomyocyte dysfunction through $\mathrm{NAD}^{+}$depletion in experimental atrial fibrillation. Nat. Commun. 10, 1307 (2019).

248. Nagy, L. et al. Olaparib induces browning of in vitro cultures of human primary white adipocytes. Biochem. Pharmacol. 167, 76-85 (2019).

249. Lee, Y. et al. Parthanatos mediates AIMP2-activated age-dependent dopaminergic neuronal loss. Nat. Neurosci. 16, 1392-1400 (2013).

250. Teng, F. et al. Neuroprotective effects of poly(ADPribose)polymerase inhibitor olaparib in transien cerebral ischemia. Neurochem. Res. 41, 1516-1526 (2016)

251. Kapoor, K., Singla, E., Sahu, B. \& Naura, A. S. PARP inhibitor, olaparib ameliorates acute lung and kidney injury upon intratracheal administration and kidney injury upon intratracheal administration (2015).

252. Ghonim, M. A. et al. PARP is activated in human asthma and its inhibition by olaparib blocks house dust mite-induced disease in mice. Clin. Sci. 129 951-962 (2015).

253. Mukhopadhyay, P. et al. PARP inhibition protects against alcoholic and non-alcoholic steatohepatitis. J. Hepatol. 66, 589-600 (2017)

254. Ahmad, A. Olah, G., Herndon, D. N. \& Szabo, C. The clinically used PARP inhibitor olaparib improves organ function, suppresses inflammatory responses and accelerates wound healing in a murine model of third-degree burn injury. Br. J. Pharmacol. 175, 232-245 (2018).

255. McCullough L. D. Zeng Z Blizzard, K. K. Debchoudhury, I. \& Hurn, P. D. Ischemic nitric oxide and poly (ADP-ribose) polymerase- 1 in cerebral ischemia: male toxicity, female protection. J. Cereb. Blood Flow. Metab. 25, 502-512 (2005)

256. Charriaut-Marlangue, C. et al. Sex differences in the effects of PARP inhibition on microglial phenotypes following neonatal stroke. Brain Behav. Immun. 73 375-389 (2018).

257. Mabley, J. G. et al. Gender differences in the endotoxin-induced inflammatory and vascula responses: potential role of poly(ADP-ribose) polymerase activation. J. Pharmacol. Exp. Ther. $\mathbf{3 1 5}$ 812-820 (2005).

This is the first demonstration of sex differences in PARP activity, in an animal model of endotoxic shock.

258. Zaremba, T. et al. Poly(ADP-ribose) polymerase(PARP-1) pharmacogenetics, activity and expression analysis in cancer patients and healthy volunteers. Biochem. J. 436, 671-679 (2011).

259. Di Girolamo, M. \& Fabrizio, G. The ADP-ribosyltransferases diphtheria toxin-like (ARTDs) family: an overview. Challenges 9, 24 (2018).

260. Qin, W. et al. Research progress on PARP14 as a drug target. Front. Pharmacol. 10, 1-12 (2019).

261. Obaji, E., Haikarainen, T. $\&$ Lehtiö, L. Structural basis for DNA break recognition by ARTD2/PARP2. Nucleic Acids Res. 46, 12154-12165 (2018).
262. Hanzlikova, H., Gittens, W., Krejcikova, K., Zeng, Z $\propto$ Caldecott, K. W. Overlapping roles for PARP1 and PARP2 in the recruitment of endogenous XRCC1 and PNKP into oxidized chromatin. Nucleic Acids Res. 45, 2546-2557 (2017).

263. Thomas, C., Ji, Y., Lodhi, N., Kotova, E., Pinnola, A. D. Golovine, K., Makhov, P., Pechenkina, K., Kolenko, V. \& Tulin, A. V. Non-NAD-like poly(ADP-ribose) polymerase- 1 inhibitors effectively eliminate cancer in vivo. EBioMedicine 13, 90-98 (2016).

264. Wang, Y. Q. et al. An update on poly(ADP-ribose) polymerase-1 (PARP-1) inhibitors: opportunities and challenges in cancer therapy. J. Med. Chem. $\mathbf{5 9}$, 9575-9598 (2016).

265. Wahlberg, E. et al. Family-wide chemical profiling and structural analysis of PARP and tankyrase inhibitors. Nat. Biotechnol. 30, 283-288 (2012).

266. Thorsell, A. G. et al. Structural basis for potency and promiscuity in poly(ADP-ribose) polymerase (PARP) and tankyrase inhibitors. J. Med. Chem. 60, 1262-1271 (2017).

267. Sherstyuk, Y. V. et al. Design, synthesis and molecular modeling study of conjugates of ADP and morpholino nucleosides as a novel class of inhibitors of PARP-1, PARP-2 and PARP-3. Int. J. Mol. Sci. 21, E214 (2019).

268. Farrés, J. et al. PARP2 is required to maintain hematopoiesis following sublethal $\gamma$-irradiation in mice. Blood 122, 44-54 (2013).

269. Ali, S. O., Khan, F. A., Galindo-Campos, M. A. \& Yêlamos, J. Understanding specific functions of PARP-2: new lessons for cancer therapy. Am. J. Cancer Res. 6 , 1842-1863 (2016)

270. Popoff, I., Jijon, H., Monia, B., Tavernini, M., Ma, M. McKay, R. \& Madsen, K. Antisense oligonucleotides to poly(ADP-ribose) polymerase-2 ameliorate colitis in interleukin-10-deficient mice. J. Pharmacol. Exp. Ther 303, 1145-1154 (2002)

271. Kamboj, A et al. Poly(ADP-ribose) polymerase 2 contributes to neuroinflammation and neurological dysfunction in mouse experimental autoimmune encephalomyelitis. J. Neuroinflammation 10, 49 (2013).

272. Lu, A. Z. et al. Enabling drug discovery for the PARP protein family through the detection of mono-ADPribosylation. Biochem. Pharmacol. 167, 97-106 (2019).

273. Hsiao, S. J. \& Smith, S. Tankyrase function at telomeres, spindle poles, and beyond. Biochimie 90 83-92 (2008)

274. Ye, J. Z. $\&$ de Lange, T. TIN2 is a tankyrase 1 PARP modulator in the TRF1 telomere length control complex. Nat. Genet. 36, 618-623 (2004).

275. Ferri, M. et al. Targeting Wnt-driven cancers: discovery of novel tankyrase inhibitors. Eur. J. Med. Chem. 142, 506 (2017).

276. Lehtiö, L., Chi, N. W. \& Krauss, S. Tankyrases as drug targets. FEBS J. 280, 3576-3593 (2013)

277. Kamal, A., Riyaz, S., Srivastava, A. K. \& Rahim, A Tankyrase inhibitors as therapeutic targets for cancer. Curr. Top. Med. Chem. 14, 1967-1976 (2014).

278. Riffell, J. L., Lord, C. J. \& Ashworth, A. Tankyrasetargeted therapeutics: expanding opportunities in the PARP family. Nat. Rev. Drug Discov. 11, 923-936 (2012).

279. Plummer, E. R. et al. First-in-human phase 1 study of the PARP/tankyrase inhibitor 2X-121 (E7449) as monotherapy in patients with advanced solid tumors and validation of a novel drug response predictor (DRP) mRNA biomarker. J. Clin. Oncol. 36, S2505 (2018).

280. Rodriguez-Vargas, J. M., Nguekeu-Zebaze, L. ¿ Dantzer, F. PARP3 comes to light as a prime target in cancer therapy. Cell Cycle 18, 1295-1301 (2019).

281. Beck, C., Robert, I., Reina-San-Martin, B., Schreiber, V. $\&$ Dantzer, F. Poly(ADP-ribose) polymerases in double-strand break repair: focus on PARP1, PARP2 and PARP3. Exp. Cell Res. 329, 18-25 (2014).

282. Lindgren, A. E. et al. PARP inhibitor with selectivity toward ADP-ribosyltransferase ARTD3/PARP3. ACS Chem. Biol. 8, 1698-1703 (2013).

283. Sharif-Askari, B., Amrein, L., Aloyz, R. ¿ Panasci, L. PARP3 inhibitors ME0328 and olaparib potentiate vinorelbine sensitization in breast cancer cell lines. Breast Cancer Res. Treat. 172, 23-32 (2018).

284. Brunyanszki, A., Szczesny, B., Virăg, L. \& Szabo, C. Mitochondrial poly(ADP-ribose) polymerase: the Wizard of Oz at work. Free Radic. Biol. Med. 100 257-270 (2016)

285. Maciag, A. E. et al. Nitric oxide (NO) releasing poly ADP-ribose polymerase 1 (PARP-1) inhibitors targeted to glutathione S-transferase $\mathrm{P} 1$-overexpressing cancer cells. J. Med. Chem. 57, 2292-2302 (2014). 
286. Gallyas, F. Jr, Sumegi, B. \& Szabo, C. Role of Akt activation in PARP inhibitor resistance in cancer. Cancers 12, 532 (2020).

287. Bonfiglio, J. J. et al. Serine ADP-ribosylation depends on HPF1. Mol. Cell 65, 932-940 (2017).

288. Gibbs-Seymour, I., Fontana, P., Rack, J. G. M. \& Ahel, HPF $1 / C 4$ orf27 is a PARP-1-interacting protein that regulates PARP-1 ADP-ribosylation activity. Mol. Cell 62, 432-442 (2016)

289. Bartlett, E. et al. Interplay of histone marks with serine ADP-ribosylation. Cell Rep. 24, 3488-3502 (2018).

290. Han, W., Li, X. \& Fu, X. The macro domain protein family: structure, functions, and their potential therapeutic implications. Mutat. Res. 727, 86-103 (2011).

291. Barkauskaite, E., Jankevicius, G., Ladurner, A. G. Ahel, I. \& Timinszky, G. The recognition and removal of cellular poly(ADP-ribose) signals. FEBS J. $\mathbf{2 8 0}$, 3491-3507 (2013).

292. Krietsch, J. et al. Reprogramming cellular events by poly(ADP-ribose)-binding proteins. Mol. Aspects Med 34, 1066-1087 (2013)

293. Rack, J. G., Perina, D. \& Ahel, I. Macrodomains: structure, function, evolution, and catalytic activities Annu. Rev. Biochem. 85, 431-454 (2016).

294. Jonsson, P. et al. Tumour lineage shapes BRCA mediated phenotypes. Nature 571, 576-579 (2019)

295. Curtin, N. J., Drew, Y. \& Sharma-Saha, S. Why BRCA mutations are not tumour-agnostic biomarkers for PARP inhibitor therapy. Nat. Rev. Clin. Oncol. 16, 725-726 (2019).
296. New REF Gentles, L. et al. Exploring the frequency of homologous recombination DNA repair dysfunction in multiple cancer types. Cancers 11, 354 (2019).

297. Patterson, M. J. et al. Assessing the function of homologous recombination DNA repair in malignant pleural effusion (MPE) samples. Br. J. Cancer 111, 94-100 (2014).

298. Alves-Lopes, R. \& Touyz, R. M. Poly(ADP-ribose) polymerase-1 (PARP-1) - a novel target in aortic aneurysm. Hypertension 72, 1087-1089 (2018).

299. Sahaboglu, A. et al. Drug repurposing studies of PARP inhibitors as a new therapy for inherited retinal degeneration. Cell. Mol. Life Sci. 77, 2199-2216 (2020).

300. Rao, P. D. et al. 'PARP'ing fibrosis: repurposing poly (ADP-ribose) polymerase (PARP) inhibitors. Drug Discov. Today https://doi.org/10.1016/j.drudis. 2020.04.019 (2020)

301. Curtin, N. et al. Repositioning PARP inhibitors for SARS-CoV-2 infection (COVID-19); a new multipronged therapy for ARDS? Br J. Pharmacol. https://doi. org/10.1111/bph.15137 (2020).

302. Szabo, C., Martins, V. \& Liaudet, L. Poly(ADP-ribose) polymerase inhibition in acute lung injury: a re-emerging concept. Am. J. Respir. Cell. Mol. Biol. https://doi.org/10.1165/rcmb.2020-0188TR (2020).

\section{Acknowledgements}

The research of N.J.C. in the field of PARP has been supported by grants from Cancer Research UK, Cancer Research UK Development Committee, the Association for International Cancer Research (06-0031), the Biotechnology and Biological
Sciences Research Council, the Bone Cancer Research Trust, the JGW Patterson Foundation, Newcastle Healthcar Charity, the Northern Cancer Care $\&$ Research Society, the Academy of Medical Sciences (NIFIR1\181894) and the UKIndia Education and Research Initiative/British Council (DST/ INT/UK/P-134/2016). The research of C.S. in the field of PARP is supported by grants from the Swiss National Foundation (31003A_179434) and the Swiss State Secretariat for Education, Research and Innovation (SMG 1927).

Author contributions

The authors contributed equally to all aspects of the article.

\section{Competing interests}

C.S. has no conflicts of interest to declare. N.C. has served on the scientific advisory boards of various companies making PARP inhibitors (AbbVie, BioMarin, Eisai and Tesaro) and other DNA damage response inhibitors (Sierra). She has received royalty payments from the commercial development of Rubraca, which have been used to fund her group's research and to establish the Curtin PARP (Passionate Realizh and tour Potalial) Fund at the Com (Passion Found (UK). Her PARP-related work has been supported by funding from Agouron Pharmaceuticals, Pfizer, Clovis, BioMarin and BiPar Sciences. 